\title{
CORSO Y GUERRA NAVAL EN EL GOLFO DE CÁDIZ DURANTE LA SEGUNDA GUERRA ANGLO-NEERLANDESA (1665-1667)
}

\section{JESÚS HERNÁNDEZ SANDE GRUPO DE INVESTIGACIÓN HUM-838 DE LA UNIVERSIDAD DE HUELVA}

RESUMEN: Durante el desarrollo de la Segunda Guerra Anglo-Neerlandesa, el puerto de Cádiz y las aguas circundantes fueron escenario de los combates entre ambas armadas y numerosos apresamientos por parte de corsarios. Este conflicto coincidió en el tiempo con la fase final de la Guerra de Restauración Portuguesa, en la que Portugal y su aliada Inglaterra se enfrentaron con España. La prensa de la época y los fondos de los Protocolos Notariales de Cádiz son fundamentales para acercarse a aquellas acciones. El artículo analiza las actuaciones de corsarios ingleses y holandeses que aprovecharon la inestabilidad del momento, e incluye la transcripción del pregón y subasta de una presa, una tipología poco habitual.

PALABRAS CLAVE: Guerra naval; Holanda; Inglaterra; corsarios; Cádiz.

\section{PRIVATEERING AND NAVAL WARFARE IN THE GULF OF CÁDIZ DURING THE SECOND ANGLO-DUTCH WAR (1665-1667)}

\begin{abstract}
During the Second Anglo-Dutch War, the port of Cádiz and the surrounding waters were the scene of the struggle between the two navies and numerous prizes were made by the privateers. This conflict coincided in time with the final phase of the Portuguese Restoration War, in which Portugal and its ally England clashed with Spain. The press of the period and the Notarial Records of Cádiz are essentials to know more about these actions. This paper analyzes the activities of privateers of England and the Dutch Republic taking advantage of the instability of the moment, and it includes a transcript of the announcement and auction of a prize, an unusual type of document.
\end{abstract}

KEYWORDS: Naval warfare; Dutch Republic; England; privateers; Cádiz. 


\section{Cádiz: puerto comercial floreciente}

A partir de mediados del siglo XVII, Cádiz mantenía su carácter de posición estratégica y era un nodo comercial de gran importancia que hundía sus raíces en los siglos anteriores, en los que jugó el papel de escala en la ruta que conectaba el Mediterráneo y el Atlántico. Frente a otros lugares del golfo homónimo, el puerto gaditano incrementaba poco a poco su relevancia, ofreciendo ventajas comerciales, fiscales o logísticas suficientes y sobradas como para terminar optando de pleno derecho a la reubicación de la Casa de la Contratación de Indias en el siglo XVIII ${ }^{1}$. Además, el desarrollo particular del litoral gaditano permitió una red organizada e interconectada de puertos a la que Cádiz no era ajena. El Puerto de Santa María o Sanlúcar de Barrameda, entre otros núcleos fundamentales, constituyeron desde finales de la Edad Media un área comercial muy activa, con una dinámica propia $^{2}$.

Con decenas de casas mercantiles extranjeras establecidas en su núcleo urbano, un puerto transitado por embarcaciones de las principales naciones occidentales del momento, y unos muelles colmados de bienes en constante carga y descarga, Cádiz era protagonista del fluir de los tiempos. En la década de los sesenta del siglo XVII, tras vivir un período de estancamiento comercial, la ciudad conoció un período de recuperación -que se tradujo también en un aumento poblacional- desembocando en un incremento notable de las exportaciones a partir de $1668^{3}$. Por otra parte, aunque determinar el número exacto de extranjeros establecidos en Cádiz resulta problemático para el siglo XVII, se constata que casi un centenar de comerciantes reputados de otras nacionalidades residía allí en $1673^{4}$. De entre estas colonias extranjeras destacaban la británica (ingleses, irlandeses o escoceses), la holandesa o la francesa.

Las guerras supusieron la perturbación de los flujos comerciales de Cádiz, pero también una oportunidad de negocio a través de las empresas de corso. Para los mercaderes y comerciantes ingleses, holandeses, franceses, hamburgueses, suecos o genoveses, entre

\footnotetext{
${ }^{1}$ Véase el estudio CARRASCO GONZÁLEZ, María Guadalupe: Los instrumentos del comercio colonial en el Cádiz. del siglo XVII (1650-1700), Madrid, Banco de España, 1996.

${ }^{2}$ Consúltense, entre otros, BUSTOS RODRÍGUEZ, Manuel: Cádiz en el sistema atlántico. La ciudad, sus comerciantes y la actividad mercantil (1650-1830), Madrid, Sílex, 2005; IGLESIAS RODRÍGUEZ, Juan José: "El complejo portuario gaditano en el siglo XVIII", e-Spania: revue interdisciplinaire d'études hispaniques médiévales et moderne, 25 oct. 2016 [en línea], https://e-spania.revues.org/25989.

${ }^{3}$ BUSTOS RODRÍGUEZ, Manuel: op. cit., p. 78.

4 A estos habría que sumar a los dedicados a otros oficios o profesiones (hombres de mar, artesanos, etc.), más la población flotante habitual. Véase CARRASCO GONZÁLEZ, María Guadalupe: Comerciantes y casas de negocios en Cádiæ, 1650-1700, Cádiz, Universidad de Cádiz, 1997.
} 
otros, la inestabilidad conducía a represalias, ataques injustificados, embargos y pérdidas. Además, las naves debían desviarse a otros puertos neutrales, bien por ruptura directa de relaciones, bien por el peligro ante la presencia de armadas y corsarios que depredaban las aguas cercanas ${ }^{5}$. En este contexto, los barcos armados en corso en Cádiz suponían una forma de aprovechar las circunstancias y alcanzar beneficios, participando patrones y armadores de las mismas naciones implicadas en las guerras -pero no solo- en una lucrativa forma de ayudar a los intereses de sus respectivos gobiernos.

\section{El estallido de la guerra entre Holanda e Inglaterra}

"Diego Coningan y Juan Banes, veçinos desta dicha çiudad (...) apostaban y apostaron, el uno contra el otro y el otro contra el otro, que si la paz entre Ynglaterra y los Estados Generales de Olanda se hiçiere en todo este dicho año, el dicho Diego Coningan dará y pagará al dicho Juan Vanes (...) dosientos pesos de plata de a ocho reales cada uno (...) y si no se hiçiere entre el dicho Reyno de Yngalaterra (sic) y dichos Estados Generales de Olanda en todo este dicho año, el dicho Juan Vanes dará y pagará al dicho Diego Coningan (...) sien pesos de plata de a ocho reales cada uno"6

Con estas palabras dos vecinos de Cádiz, uno de origen inglés, el otro holandés, comprometían económicamente su conjetura acerca del posible final de la guerra que había estallado entre sus respectivas naciones el 4 de marzo de 1665. El inglés no tuvo suerte en su previsión: el conflicto se alargaría hasta el 31 de julio de 1667, momento de la firma del Tratado de Breda. La Segunda Guerra Anglo-Neerlandesa tuvo la misma causa fundamental que motivó la primera (1652-1654), esto es, la competencia marítima-mercantil entre la República de las Provincias Unidas de los Países Bajos y el Reino de Inglaterra ${ }^{7}$. Fue esta una guerra que implicó un número de marineros y embarcaciones sin precedentes. Como indica el historiador Gijs Rommelse, a la firma del tratado de paz, Europa asistiría asombrada a un enfrentamiento de tal dimensión y violencia en el mar que pudo dar lugar a una batalla como la de los Cuatro Días (11-14 junio 1666), cerca de las costas de Flandes e Inglaterra, aún hoy

\footnotetext{
${ }^{5}$ Op. cit., pp. 22 y ss.

${ }^{6}$ Archivo Histórico Provincial de Cádiz (AHPC), Protocolos Notariales de Cádiz, leg. 2105, fol. 164, 7 de agosto de 1666. Es conveniente señalar, para facilitar la labor de otros investigadores e interesados, que en el fondo de Protocolos Notariales de Cádiz del Archivo Histórico Provincial de Cádiz la foliación se reinicia con cada año contenido en los diversos legajos. Por ello es importante, para localizar los documentos, acudir al año y consultar los folios indicados de dicho año.

${ }^{7}$ Para más información se recomienda, entre otros, la lectura de ISRAEL, Jonathan: The Dutch Republic: Its Rise, Greatness and Fall, 1477-1806, Oxford, Clarendon Press, 1995; HAINSWORTH, Roger y CHURCHES, Christine: The Anglo-Dutch Naval Wars 1652-1674, Gloucestershire, Sutton Pub., 1998. El fomento de las patentes y armamentos de corso por ambos bandos en puertos como el de Cádiz puede rastrearse en la última obra referida a partir de la página 115 .
} 
uno de los combates navales más largos y sangrientos de la Historia ${ }^{8}$. En este segundo episodio del enfrentamiento entre Inglaterra y los Países Bajos, la República Neerlandesa se encontraba mejor preparada que en el conflicto anterior y ello pudo constatarse en el propio devenir de la guerra. El acuerdo final entre ambos contendientes supuso una victoria considerable del Gran Pensionario Johan de Witt, que consolidó a la República como una de las grandes potencias del momento ${ }^{9}$. No obstante, la rivalidad entre ambos países volvería a manifestarse en corto espacio de tiempo, dando lugar a la Tercera Anglo-Neerlandesa (16721674). De hecho, otra corriente de opinión historiográfica considera que el Tratado de Breda solo fue un pequeño respiro en una decadencia evidente y marcada de la hegemonía económica y comercial holandesa, en favor de Inglaterra y Francia.

España no mantuvo una posición completamente equidistante, pues Inglaterra, aliada de una Portugal en guerra abierta por su independencia de la Monarquía Hispánica, despertaba muchas menos simpatías que las Provincias Unidas ${ }^{10}$. El conflicto entre Inglaterra y Holanda significó un respiro para los intereses españoles, pues durante estos años las fuerzas navales del tradicional enemigo inglés no continuaron presionando en ámbitos como el mar Caribe y otras aguas de las Indias Occidentales, así como la Península Ibérica. El acercamiento entre el rey Felipe IV y De Witt proporcionaría una poderosa entente ante ingleses y portugueses, aunque esta alianza nunca llegó a formalizarse. Felipe IV moriría en septiembre de 1665, y su hijo Carlos II sería entonces aún muy joven como para asumir la corona. Por ello, la reina Mariana de Austria asumiría la regencia, asistida por una Junta ${ }^{11}$. En 1667, Francia invadió los Países Bajos españoles, marcando el inicio de la Guerra de Devolución (1667-1668) entre España y Francia, que ganó esta última. Fue un factor decisivo a la hora de acelerar el fin de la Segunda Guerra Anglo-Neerlandesa.

En Cádiz, el inicio de la Segunda Guerra Anglo-Neerlandesa supuso que sus autoridades actuaran contra los cónsules de una y otra nación, que no realizaron las diligencias necesarias para respetar la neutralidad de dicho puerto. El 16 de mayo se

\footnotetext{
${ }^{8}$ ROMMELSE, Gijs: The Second Anglo-Dutch War (1665-1667): international raison d'état, mercantilism and maritime strife, Hilversum, Uitgeverij Verloren, 2006, p. 195. También destacó la batalla de Medway o Chatham (6-14 junio de 1667) en Kent (Inglaterra), donde la armada inglesa fue destruida parcialmente.

9 Para entender la prominente posición de Holanda en esta época, así como su resiliencia a la hora de recuperarse de los daños causados a su comercio por estas confrontaciones, consúltese VAN DEN BOOGAART, Ernst: La expansión holandesa en el Atlántico, 1580-1800, Madrid, Editorial MAPFRE, 1992.

${ }^{10}$ Para entender esta relación y su evolución, léase HERRERO SÁNCHEZ, Manuel: El acercamiento bispanoneerlandés (1648-1678), Madrid, CSIC, 2000.

11 Sobre los movimientos diplomáticos de los embajadores en la corte de Madrid durante estos años, se recomienda la lectura de OLIVÁN SANTALIESTRA, Laura: Mariana de Austria: imagen, poder y diplomacia de una reina cortesana, Madrid, Editorial Complutense, 2006, pp. 253 y ss.
} 
encontraba preso el cónsul holandés, Abraham Vanderute o Vanderhuten ${ }^{12}$. Poco después sería liberado bajo fianza. Igualmente, el cónsul inglés Martín Visconde también se encontró en la cárcel pública, aunque tardó un día más en conseguir un fiador que avalara su salida ${ }^{13}$.

\section{E1 desarrollo de las acciones navales}

El 10 de mayo de 1665 se reflejaba en la prensa de la época, concretamente en La Gaceta de Amsterdam, uno de los primeros combates importantes entre naves holandesas e inglesas ${ }^{14}$. Dos navíos holandeses armados en Cádiz interceptaron, a la vista del puerto, la fragata inglesa 'La Corona'. Esta había partido de Tánger en dirección a Lisboa, y estaba mejor artillada y guarnecida que las naves atacantes. En su salida en pos de la presa, uno de los navíos varó en algún bajío de la bahía, mientras que el otro, el 'Tres Reyes', combatió con la fragata hasta llegar la medianoche. Los ingleses solicitaron tregua hasta el amanecer y les fue concedida. Con la salida del sol se reanudó la lucha, a pesar de que ya habían muerto los oficiales holandeses al mando en el combate anterior. La fragata consiguió finalmente refugiarse en Cádiz, seguida de cerca por los holandeses. La neutralidad del puerto y la necesidad de reparaciones hicieron que ambas naves acordasen un alto el fuego. Señalaba la prensa flamenca -no hay que olvidar que es solo una versión de los hechos- que los hombres de 'La Corona' hicieron correr la noticia de que partirían al día siguiente y que combatirían contra cualquier embarcación que les saliera al paso. Sin embargo, la nave que había luchado todo el día anterior contra ellos no estuvo lista para seguirles, y el otro barco, ya liberado de su atolladero, no fue lo suficientemente rápido para dar caza a 'La Corona'. Pero este fue un respiro momentáneo para los ingleses. La fragata británica se encontró en la ruta de la escuadra del capitán holandés Mewen ${ }^{15}$, compuesta de seis naves y tres presas inglesas. 'La Corona’ ya no tuvo tanta suerte y no pudo escapar. Es muy interesante observar cómo desde

12 "por aver contrabenido a la horden que en siete deste mes dio por su carta el excelentísimo señor Duque de Medinazeli de los Consexos de Estado y Guerra, Capitán General del Mar Ocçéano (sic), Costas y Exércitos del Andalucía, que fue para que se dispusiese las navegaçiones de los navíos yngleses y olandeses de manera que en veynte y quatro oras de como vbiesen salido los de vna naçión, no saliesen los de la otra" (AHPC, Protocolos Notariales de Cádiz, leg. 1796, fol. 50, 16 de mayo de 1665). Sobre los comerciantes y hombres de negocios holandeses asentados en Cádiz es conveniente la consulta de CRESPO SOLANA, Ana: "Merchants and observers. The Dutch Republic's commercial interests in Spain and the merchant community in Cadiz in the eighteenth century", Dieciocho, 32.2, 2009, pp. 1-31. Especial interés tiene el listado de mercaderes registrados en el Consulado Holandés o pertenecientes a la Nación Flamenca.

${ }^{13}$ AHPC, Protocolos Notariales de Cádiz, leg. 1796, fol. 52, 17 de mayo de 1665.

${ }^{14}$ La Gazette d'Amsterdam, n. 24. Los números de la gaceta utilizados para este artículo se encuentran en The National Archives (TNA) de Kew (Londres, Reino Unido).

${ }^{15}$ Los nombres que aparecen en prensa y documentos originales tienden a ser deformaciones -incluso en lengua vernácula, pues su grafía con respecto a la actual ha sufrido modificaciones-. Quizás se tratara de un nombre de sonoridad similar a Meeuwszoon/Meussen. 
la gaceta holandesa se reflejaba el apoyo español a su bando, indicándose que los habitantes de Cádiz tenían en muy poca estima a los ingleses y que procedieron a regalar, como recompensa por su valentía, una cadena de oro a la hija del capitán fallecido del 'Tres Reyes'. Ese capitán sería Dirck Jansse Duysent. El otro navío también puede ser identificado: el 'Gran San Jorge', comandado por Jacob Pietersse Twisk ${ }^{16}$.

Pocos meses después del estallido del conflicto, en el verano de 1665, se producía el apresamiento de los navíos 'La Encarnación' y ‘El Diamante'. Antonio de Polanco -vecino y natural de Málaga-, Juan Bueno Guipponi -veneciano avecindado en dicha ciudad- y Bartolomé Galeoto Lomelin -genovés y vecino de Antequera- eran algunos de los dueños y partícipes en ambas naves y sus cargamentos de mercancías. En 22 de junio "fueron apresados en esta costa (de Cádiz) por los baxeles de la esquadra de guerr[a] [o]landesa que navega en ella" ${ }^{17}$. Los autos sobre la restitución de todo ello se desarrollaban en aquel momento en El Puerto de Santa María contra el cabo y comandante de la escuadra, así como contra el Comisario de los Estados de Holanda en los puertos de la zona, Gisberto Mels ${ }^{18}$. Un poder aclara que 'La Encarnación' era un navío de porte de 300 toneladas, de fábrica y capitán venecianos, siendo este Juan Pretina. El veneciano habría salido del puerto de Málaga para ir a Ostende con una carga de lana, varillas y sal ${ }^{19}$, y habría llegado al Estrecho de Gibraltar en compañía:

“de otro navío que seguía el mismo viaje, nombrado 'El Diamante', de que era capitán Reynaldo Doze, de nazión liornés; hallándonos menos de veinte leguas del Estrecho, después de desenbocados el día que se contaron veinte y dos del mes de junio passado deste presente año, les dieron caça tres navíos. Y aviendo reconosido por sus vanderas que eran olandeses, los aguardasen. Y el comandante y cavo dellos, que paressió ser Pedro Midelano, olandés, y todos tres navíos de guerra, me apresaron; y así de mi compañía, con supuestos y pretextos siniestros, que para ello tomaron. Y se apoderaron de anvos vajeles, sacaron a gente y metieron otra, y les trajeron a este puerto y vahía, donde les an tenido y tienen para llevarlos como con efeto de próxsimo (sic) los llevarán, en compañía de otros, a Olanda" 20

\footnotetext{
${ }^{16}$ Habrían salido inicialmente de El Puerto de Santa María (CORNELIS DE JONGE, Johannes: Geschiedenis van het Nederlandsche zeewezen, Haarlem, vol. II, 1869, p. 54).

${ }^{17}$ AHPC, Protocolos Notariales de Cádiz, leg. 1423, fol. 535, 30 de agosto de 1665.

18 Ante el Duque de Medinaceli, escribano de guerra Pedro de Baena.

${ }^{19}$ Los cargadores en Málaga y otros puertos del Levante eran, en efecto, "Juan Bueno Guigent, don Antonio Camila y don Bartolomé Galiotelo Melin, de nazión venesiano y jinobeses, vezinos el primero de Málaga y los segundos de la çiudad de Antequera" (AHPC, Protocolos Notariales de Cádiz, leg. 1094, fol. 522, 23 de agosto de 1665).

${ }^{20} \mathrm{El}$ poder lo otorgaba a "Phelipe Petrina, mi hermano, y a Gaspar Valthasar, condestable que fue del dicho mi navío, anbos venesianos, residentes en esta çiudad" para que continuaran las diligencias iniciadas por él y el otro capitán contra sus captores.
} 
En noviembre de 1665 se mantenía otro pleito entre Mels y Abraham Vanderhuten, cónsul de la nación holandesa en Cádiz, acerca de "haver un navío de guerra de Holanda, devajo del seguro deste puerto, apresado vna balandra ynglesa nombrada 'La Cattalina Real', de que fue maestre Guillermo Guebar" ${ }^{21}$. La nave había sido cargada por Diego Gorman, residente en Cádiz, con vinos de Francia. Como resultado de los autos judiciales, las autoridades ordenaron el arresto de ambos, cónsul y comisario. Otro documento de octubre da cuenta con mayor detalle:

“capitán Diego Gorman, de nasión yrlandés (...) dueño que soy en parte y consignador en el todo de la balandra nombrada 'La Real Catalina de Londres' (...) que apresó el nauío nombrado 'El Profeta Elías', [o]landés, entre los baluartes de San Phelipe y San[ta] C[a]talina desta çiudad el día diez y siete de setiembre pasado (...) Gualtero Uuobar, maestre de la dicha balandra" 22

En abril de 1666 se señala en otro testimonio que 'El Profeta Elías' se encontraba bajo el mando del cabo comandante Juan Gidionsen Verburque o Jan Gideonszoon Verburgh $^{23}$. El cónsul de Holanda tuvo que afrontar la restitución de la presa, valorada en 5.358 pesos. La prensa zelandesa reflejó la información llegada de Londres el 25 de junio: 'Les dernieres lettres de Cadix donnent avis qu'on y a arrété notre Consul prisonnier sur ce qu'un de nos avanturiers ou vaisseaux en avoit enlevé un Hollandois sous le canon de cette ville ${ }^{224}$. A petición del cónsul Visconde, se procedió al embargo de otra presa inglesa realizada por Gidionsen antes de partir de la bahía: el navío 'El Guillermo'25.

Ese mismo mes se indicaba en otro documento notarial que había sucedido un hecho similar un tiempo antes, pero siendo los ingleses los que habrían capturado una embarcación holandesa. El cónsul entonces de esta última nación, Jacome Vandenhoue, y Joan Van Nes, hombre de negocios de Holanda en Cádiz, otorgaron poder al procurador Juan Muñoz Villarán para defenderles en la querella que mantenían contra el general Jerónimo Sinitt, quien

\footnotetext{
${ }^{21}$ AHPC, Protocolos Notariales de Cádiz, leg. 1796, fol. 170, 9 de noviembre de 1665. Sobre el capitán Guillermo Guebar, inglés, se conservan diversos documentos. En 1666 mantenía querella criminal iniciada en abril de 1664 con los capitanes de mar y guerra Juan Brians y Mateo Martín, el piloto Joaquin Lebreten y el guardián Nicolás Haubin, todos tripulantes del navío 'Santa Elena' (AHPC, Protocolos Notariales de Cádiz, leg. 1424, fols. 97 y 176, 5 y 28 de febrero de 1666).

22AHPC, Protocolos Notariales de Cádiz, leg. 1301, fol. 226, octubre de 1665. En octubre, precisamente, hubo un sonado combate entre naves inglesas y holandesas en las aguas entre Tánger y Cádiz (The London Gazette, n. 1, 7 de noviembre de 1665).

${ }^{23}$ AHPC, Protocolos Notariales de Cádiz, leg. 1796, fol. 100, 21 de abril de 1666. Desde, al menos, diciembre de 1665 se encontraba en la zona esperando interceptar embarcaciones inglesas (JANSZ, Broer: Tÿdinghe uyt verscheyde quartieren, Amsterdam, 1666, n. 2 y 4).

${ }^{24}$ La gazette d'Amsterdam, n. 26.

${ }^{25} \mathrm{Su}$ nombre completo sería 'El Guillermo y $\mathrm{M}^{\circ}$. . No está clara la interpretación de la palabra comprimida.
} 
se encontraba al mando de una escuadra de guerra inglesa que navegaba por aguas de Cádiz. Al parecer, Sinitt habría apresado en vulneración del "seguro deste puerto e vahía y debajo de la artillería desta plaza, el navío nonbrado 'San Pedro', maestre Vberto Gerardo, olandés, que venía a entrar en él con la carga de mercaderías"26.

Escuadras navales y corsarios recorrían las rutas comerciales y de abastecimiento del enemigo. El 13 de julio de 1665 se trataba en el Almirantazgo inglés el caso del 'San Salvador ${ }^{27}$. Se trataba de una nave de vasallos del Rey de España, su maestre Cornelius Gettaer, que viajaba de Ostende a Cádiz. Dos fragatas inglesas la aprehendieron y sus mercancías y tripulación fueron descargadas en la costa de Dover. Antonio de Villaviciosa, como representante de Felipe IV, presentó queja acerca de esta acción. Por otra parte, en noviembre de 1665, el sobrecargo napolitano Genaro Longo declaró en Cádiz que, en febrero de ese año, encontrándose en el puerto de Málaga el navío holandés 'La Señora Teodora': "por caussa de hallarse en el Estrecho diferentes nauíos de yngleses y aber rompido autos con los holandeses, el dicho capitán (...) no determinó a hazer viage a esta dicha ciudad (...) por temor de que no se le perdiesse”28. Su capitán era Pedro Siniona Wenebesin. En 1666, un poder del inglés George Walles, residente en Cádiz, indicaba que tanto él mismo como George Sile, también inglés y morador en Sanlúcar de Barrameda, habrían adquirido en diciembre de 1665 una nave apresada, concretamente de mano del cabo Jan Gideonszoon Verburgh. Era una embarcación de fábrica holandesa y de porte de 60 toneladas, valorada en 680 pesos de plata. Lamentablemente, no se facilita el nombre de la nave, solo se indica que "viniendo del puerto de Plemua ${ }^{29}$ con bastimentos para Tanjar fue apresado de los navíos de la dicha esquadra y traído a este" ${ }^{30}$.

El 13 de marzo de 1667 se escribía desde Cádiz, según recoge la Gaceta ordinaria de Amsterdam, sobre una presa inglesa conducida a la bahía ${ }^{31}$. La noticia llegaba de Málaga: "qu’un vaisseau marchand de Zelande nommé 'Le Grifon', parti de Cadix pour aller à Malgue (sic), a fait rencontre d'un autre vaisseau marchand Anglois a mi-chemin, \&o l'a pris \&o mené a Cadix pour le vendre plus avantageusement". En La Gaceta de Londres se mencionaba, en cambio, la llegada a Cádiz unos

26AHPC, Protocolos Notariales de Cádiz, leg. 1796, fol. 96, 10 de abril de 1666.

27 TNA, Privy Council Registers (PC) 2/59, fol. 214.

${ }_{28}$ Transportaba trigo por orden del Príncipe de Sansevero (AHPC, Protocolos Notariales de Cádiz, leg. 974, fol. 355, 16 de octubre de 1665).

29 Plymouth.

${ }^{30}$ AHPC, Protocolos Notariales de Cádiz, leg. 1424, fol. 142, 16 de febrero de 1666. Quizás se tratara de una de las presas realizadas por Gidionsen que se señalan en páginas siguientes -'El Guillermo'-. El antiguo capitán fue restituido en el cargo, alguien llamado Juan -su apellido se pierde en un roto del documento-. Se procedió a volverlo a cargar con bastimentos y naranjas -que se subieron en Sevilla- para viajar a Londres.

31 Gazette ordinaire d'Amsterdam, 21 de marzo de 1667. Números disponibles en la Koninklijke Bibliotheek (Holanda) y The National Archives de Kew (Reino Unido). 
días antes de la fragata 'Constant Warwick'32, que a la altura de Lisboa trabó combate con un corsario holandés ${ }^{33}$. Aunque escapó, y estaba siendo en ese momento reparada en los astilleros gaditanos, habría perdido seis hombres y su capitán, un tal Eysam, habría fallecido a causa de un disparo en un brazo.

La violencia en el mar, no obstante, no era solo patrimonio de holandeses e ingleses. Otras embarcaciones de países no implicados en el conflicto también sufrieron ataques por naves de ambas naciones. El 19 de abril de dicho año llegaba información desde Marsella sobre un capitán francés que, al mando de dos navíos salidos de Toulon, habría luchado contra dos grandes fragatas inglesas cerca de Cádiz ${ }^{34}$. No se sabía nada de su destino.

Los apresamientos por parte de holandeses o ingleses en otros lugares de Europa dejaron así mismo huella en los registros gaditanos, incluso tras finalizar el conflicto. Así, el holandés afincado en Cádiz Cornelio Susquens refería en un poder de 16 de julio de 1665 que había comprado en enero la nao 'Santa Catalina' a su antiguo propietario y capitán, el también holandés Juan Huberto. Sin embargo:

"estando la dicha nao en la enttrada del río nonbrado 'el Elfs'35, de la çiudad de Hamburgo, la apresó vna nao de guerra del Rey de Ynglaterra (sic), yendo con ella en compañía de otras naos; la buelta de la çiudad de Londres dieron con la harmada olandesa la qual apresó la dicha mi nao y la de guerra y las demás" 36

En marzo de 1668, el comerciante genovés Juan Bernardo Graso daba poder a al holandés Esteban Boet, residente en Cádiz, como asegurador de las mercancías cargadas en un navío llamado 'El Sacrificio de Abraham', capitán Antonio Bazo. La póliza se realizó en junio de 1667 y la embarcación partió del puerto de Texel (Holanda) para arribar a la bahía de Cádiz. Sin embargo "fue apresado por yngleses o yrlandeses por la guerra que hubo entre la Corona de Ynglaterra y los Estados de las Prouincias Unidas de Olanda"37. También se vio afectado el navío 'El Contento', capitán Juan Schovers, que haciendo viaje en marzo de 1666 desde el puerto de Cádiz al de Plymouth "a sido apresado de enemigos”38.

\footnotetext{
32 De renombre en la historia de la Marina inglesa, véase LAVERY, Brian: The Ship of the Line - Volume 1: The development of the battlefleet 1650-1850, Londres, Conway Maritime, 2003, pp. 159 y ss.

33 The London Gazette, n. 145.

${ }^{34}$ Gazette ordinaire d'Amsterdam, 9 de mayo de 1667.

${ }^{35}$ El Elba.

${ }^{36}$ AHPC, Protocolos Notariales de Cádiz, leg. 2104, fol. 316, 16 de julio de 1665.

${ }^{37}$ AHPC, Protocolos Notariales de Cádiz, leg. 1426, fol. 212, 9 de marzo de 1668. Un mes después, Graso otorgaba una cesión en favor de Enrique Lepin y Juan Vey, como compañía aseguradora de las mercancías embarcadas (AHPC, Protocolos Notariales de Cádiz, leg. 1426, fol. 295, 7 de abril de 1667).

${ }^{38}$ AHPC, Protocolos Notariales de Cádiz, leg. 1425, fol. 597, 7 de junio de 1667.
} 
En 1673 se recogía en una obligación el destino del navío 'La Fortuna':

"Rodrigo Mels, vezino de la çiudad de Amsterdam, por el año passado de mill y seisçientos y sesenta y siete, cargó en el nauí[o] nombrado 'La Fortura (sic) de la Mar', capitán Volche[...]histemaker, estando en el puerto dela dicha çiudad de Ams[t]erdan, cartidad (sic) de jarçia y otros muchos peltrechos que heran para el apresto de la Real Armada del Mar Oçéano, consignados para entregar en la dicha çiudad del P[u]erto de Santa María al dicho Valentín Pérez, que asiste en la ausençia de Gisberto Mels a la cassa y negoçios de los dichos Rodrigo y Gisberto Mels. Y e así que haviendo nauegado el dicho nauío 'La Fortuna' en seguimiento de su biaje para la bahía desta çiudad, por el norte de Yngalaterra (sic), fue apresado de vn nauío de guerra del Rey de la Gran Bretaña y llevado al puerto de Galway, en Yrlanda" 39

Durante este período no solo se produjeron combates y tomas entre holandeses e ingleses, otras nacionalidades aprovecharon la caótica situación para llevar a cabo ataques y presas. Al igual que en los casos anteriormente analizados, los testimonios acerca de las víctimas se pueden encontrar bastantes años después del hecho. A modo de ejemplo es interesante analizar el caso del 'San Nicolás Tolentino'. Su cargamento de vinos tomado en Canarias por su capitán, Franes Galerio o Galesio, tenía participación de diversos mercaderes holandeses y genoveses, todos ellos asentados en Cádiz. En febrero de 1675 estos comerciantes todavía intentaban recuperar su inversión pues: "haviendo hecho viaje por junio del año pasado de seisçientos y sesenta y siete fue apresado por navío françés y llevado al puerto de Brest, donde fue detenido hasta el mes de febrero de seisçientos y sesenta y ocho"40. Cornelizen y compañía habían tenido conocimiento de que la nave se encontraba en ese momento en Londres, de ahí su pretensión de que se llevara a cabo la restitución.

\section{Corsarios holandeses e ingleses en las costas del Golfo de Cádiz}

A finales del año 1665 operaba en las costas andaluzas un corsario holandés llamado Guillermo o Willem Jansen ${ }^{41}$. Su nave es calificada en los documentos con el adjetivo "levantada", aludiendo a que actuaba en contravención de las leyes. Jansen se aprovechaba de que su embarcación parecía española -por su fábrica o tipología- para ejercer el corso de forma encubierta. En noviembre de 1665 se establecía en una fianza depositaria a favor de Diego Coningan, negociante inglés afincado en Cádiz, que:

\footnotetext{
${ }^{39}$ AHPC, Protocolos Notariales de Cádiz, leg. 1145, fol. 134, 22 de febrero de 1673.

${ }^{40}$ AHPC, Protocolos Notariales de Cádiz, leg. 2109, fol. 101, 18 de febrero de 1675. Recuérdese la Guerra de Devolución (OTERO LANA, Enrique: Los corsarios españoles durante la decadencia de los Austrias. El corso español del Atlántico peninsular en el siglo XVII (1621-1697), Ponferrada, Instituto de Estudios Bercianos, 2014, p. 317).

${ }^{41}$ No se ha considerado necesario entrar en disquisiciones sobre la diferenciación entre pirata y corsario, más que para apuntar la ilegalidad del uno frente al amparo de las autoridades de la nación emisora de la patente del otro. Se recomienda la lectura de la clásica obra de GOSSE, Philip: Historia de la piratería, Sevilla, Editorial Renacimiento, 2008.
} 
"el día ocho de otubre próximo deste dicho año Guillermo Juancen, olandés, con vn barcoluengo levantado de fábrica española apresó un nabichuelo ynglés nombrado 'La Fedelidad' (sic), de que es capitán Juan Estafor, ynglés, que avía salido con carga de vino y passa del puerto de la ciudad de Sanlúcar de Barrameda; y lo trajo con la dicha carga a la vahía desta dicha ciudad" 42

El cónsul inglés de Cádiz habría interpuesto querella al considerar que Jansen estaba soslayando la neutralidad española en la guerra entre Inglaterra y Holanda y que, por tanto, había realizado la toma de forma indebida ${ }^{43}$. El inventario de la fragatilla apresada, de 25 toneladas, incluía velamen y aparejos propios, así como quince pipas y tres cuarterolas de vino, dos barriles de alquitrán y ciento sesenta y ocho seras de pasas largas ${ }^{44}$. Varios meses después, una escritura de resguardo por el depósito de estos bienes en poder de varios hombres de negocios ingleses de Sanlúcar de Barrameda aclara el nombre de la embarcación atacante: el 'San Francisco`45. En noviembre de 1666 aún no se había resuelto la disputa entre los capitanes Willem Jansen y John Stafford, y la presa seguía embargada, por tanto, hay que esperar hasta 1670 para encontrar una nueva resolución, esta vez definitiva ${ }^{46}$. Una transacción

\footnotetext{
${ }^{42}$ AHPC, Protocolos Notariales de Cádiz, leg. 1796, fols. 162-163, 7 de noviembre de 1665. También se conserva una obligación y resguardo de Diego Coningan contra Guillermo Brum (Ibídem, fols. 164-165).

${ }^{43}$ Véase el poder otorgado por el capitán Stafford a Francisco Benefil: "Sépasse cómo yo, Juan Estafor, de naçión ynglés, estante en esta ciudad de Cádiz, dueño y maestre de una fregatilla nombrada 'La Fidelidad', digo que aviendo salido con él con carga de vino y passas del puerto de la ciudad de San Lúcar de Varrameda el día ocho de octubre próximo passado, fui apresado de vn barco luengo levantado de que es dueño Guillermo Juançen, olandés, y trajo a la vahía de dicha ciudad la dicha mi fregatilla, y en ella por don Martín Visconde, como cónsul de la nazión ynglesa, se dio querella contra el dicho Guillermo Juançen, y se resivió sierta ynformazión como parese de los autos en esta raçón hechos ante el señor governador desta ciudad y el pressente escrivano público y de la guerra, en los quales está mandado prender el dicho apresador y que se ponga y asegure de puntales adentro la dicha mi fragatilla. Y para que en mi nombre aya perssona lexítima que prosiga los dichos autos y resiva y cobre la dicha mi fragatilla y su carga, otorgo que doy (...) poder cumplido (...) a don Francisco Benefil, cónsul de la nazión ynglesa en la dicha ciudad de Sanlúcar de Varrameda, residente en esta"(AHPC, Protocolos Notariales de Cádiz, leg. 1796, fol. 160, 4 de noviembre de 1665).

$44 \mathrm{Al}$ respecto del estado de la nave se indica que: "se pone por ynbentario el casco y buque de la dicha fragatilla, de porte de veinte y sinco toneladas, poco más o menos; los árboles mayor, trinquete y mesana, arbolados con sus belas mayor y de gavia; bela del trinquete, belacho; bela de la mesana; el árbol del bauprés con su sebadera; las bergas de los dichos árboles, puestas en ellos; tres claues hordinarios; tres anclas; la harsia pendiente. Todo ello usado".
}

${ }^{45}$ AHPC, Protocolos Notariales de Cádiz, leg. 1796, fol. 31, 21 de enero de 1666. Llama la atención la existencia en Cádiz de una venta de un navío llamado 'San Francisco', de fábrica holandesa, por un capitán holandés llamado Tache o Taque Jansen, AHPC, Protocolos Notariales de Cádiz, leg. 1423, fols. 65-66, 31 de enero de 1665. La embarcación, de 300 toneladas y 26 cañones, fue vendida a unos vecinos de Cádiz. Parece difícil discernir si este Jansen tenía algo que ver con el capitán Guillermo Jansen. Todo hace pensar que se trata de una simple coincidencia, pues en el mismo legajo se puede encontrar documentación referente al navío, llamado a partir de entonces 'San Francisco y las Ánimas', que tenía como destino Honduras. Además, el tonelaje no coincide.

46AHPC, Protocolos Notariales de Cádiz, leg. 1796, fol. 267, 26 de noviembre de 1666. En agosto de ese año se vendía una fragatilla llamada 'San Francisco', por orden emanada de la corte de Madrid, a Andrés de Coninque, hombre de negocios flamenco vecino de Cádiz. Algunos datos, como el porte o la fábrica, no parecen coincidir bien, aunque se la califica de "levantada": "la fragatilla nombrada 'San Francisco', fábrica portuguesa, leuantada, de porte de sesenta toneladas, poco más o menos, surta y anclada al presente en la bahía". AHPC, Protocolos Notariales de Cádiz, leg. 1429, fols. 588-589, 25 de agosto de 1666. Parece que se trataría de otra presa realizada sobre los rebeldes portugueses. 
que ofrece además interesantes detalles acerca del caso, tales como el lugar del apresamiento: la barra de Huelva. El proceso se habría seguido ante el Gobernador de Cádiz, Martín de Zaras Bazán, y el escribano de guerra Juan Rodríguez de Medinilla. Se reconocía que Jansen hizo la presa "valiéndose para no ser conozido de la dicha embarcazión española" y se estimó que "no era justo que, a vista de los puertos de España y con vajel fabricado en ellos, en contrabenzión de las pazes, el dicho Guillermo Yansen cometiese semejantes delitos" ${ }^{\text {" }}$. El Gobernador mandó prender al capitán Jansen y embargar sus bienes y barco. El 'San Francisco' debía anclarse junto a la fragatilla inglesa, pasados los puntales del puerto gaditano. El encargado de llevarlo a cabo fue el ayudante de sargento mayor del presidio, Fernando Tenorio. Primero subió a bordo de 'La Fidelidad' y, por no disponer esta de bote alguno, la condujo hasta dar fondo frente a la puerta de la mar, en el sitio donde solían anclar las saetías y gabarras. Mandó cerrar y clavetear las escotillas y se puso al frente de una guardia que veló por su seguridad.

Sin embargo, cuando se procedió contra el 'San Francisco' y Jansen, ni barco ni capitán se encontraban ya en Cádiz. La nave había zarpado y el capitán Jansen fue declarado en rebeldía contra la justicia. La sentencia sería firme el 29 de diciembre de 1665, prohibiéndole a Jansen andar en corso con su nave en las costas españolas y se procedió a restituir 'La Fidelidad' a sus propietarios, estableciéndose que el holandés tendría que pagar 2.000 ducados además de perder su barco. Al no hallarlo, la justicia real actuaría de nuevo en 29 de octubre de 1668, siendo así cobrada la mitad de los ducados a través de "Abrahan de Breezelandes, vezino de Medelburgo (...) parte por el dicho capitán Guillermo Yansen y Thomas Aldersennett y los marineros, armadores y demás ynteresados que fueron del dicho barco lebantado nombrado 'San Francisco"'. En marzo de 1670, mediante esta concordia, los acusados obtendrían el indulto definitivo. Es interesante la mención a Tomas Aldersen o Andresen, ya que otro poder de junio de 1667 lo menciona como capitán apresador. Es probable que fuera el segundo de a bordo, teniente o segundo oficial:

"Francisco Venefil, cónsul de la nación ynglesa en la ciudad de Sanlúcar de Barrameda y residente en esta de Cádiz, en nonbre de Juan Estafor, de la dicha naçión, dueño y maestre de la fragatilla nombrada 'La Fidelidad' (...) pleyto y causa que se está siguiendo en él en grado de apelación por parte de Tomas Andresen, capitán del navío nombrado (sic), sobre que se le mandó entregar a mi parte la dicha fragatilla haviéndola apresado el dicho Tomas Andresen" 48

\footnotetext{
${ }^{47}$ AHPC, Protocolos Notariales de Cádiz, leg. 1798, fols. 34-38r, 9 de marzo y 28 de marzo de 1670.

$48 \mathrm{El}$ escribano tuvo un lapsus escribiendo y no dejó constancia del nombre del navío (AHPC, Protocolos Notariales de Cádiz, leg. 1797, fol. 190, 10 de junio de 1667).
} 
Otro de los corsarios holandeses que operaban en la zona en esos primeros momentos del comienzo de la guerra fue Dowe Harcksz. Este capitán, al contrario que Jansen, lo hacía sin generar sospecha de soslayar el marco legal del ejercicio del corso. En mayo de 1665, Harcksz se encontraba al mando del navío 'San Carlos', embarcación armada en Cádiz: "le navire du 'Saint Charles" que Messieurs les Estats des Provinces Unies ont fait equiper ici en guerre \& montet de 100 bommes \& de 24 pieces de canon" ${ }^{\text {"49 }}$. Se refería en la noticia señalada que ya hacía algún tiempo de la entrada en el puerto gaditano del 'San Carlos' con dos pequeñas presas inglesas. Tras ello, se volvió a hacer a la mar y retornó el 21 de dicho mes, con cincuenta y un prisioneros ingleses obtenidos de otra embarcación con la que combatió durante cinco horas. Se trataba del buque 'La Salamandra', el cual había partido de Londres con 400 barriles de pólvora y otras municiones para llevarlas a Tánger. Durante la lucha, el navío inglés salió ardiendo, de tal forma que los holandeses de Harcksz solo habían podido recuperar su pabellón o bandera y los mencionados prisioneros, entre los que se encontraba el propio capitán, Jean o John Ballos, quien parecía ser sobrino o pariente cercano del Gobernador de Tánger. La tripulación de Harcksz también sufrió las consecuencias del enfrentamiento, perdiendo a siete hombres, además de resultar heridos otros dieciocho o veinte marineros. En una obra holandesa contemporánea, fechada en 1666, y que versa sobre los diversos combates entre ingleses y holandeses, se señala que 'La Salamandra' disponía de veintiocho piezas de artillería ${ }^{50}$. Al parecer, fue interceptada cuando ya habían transcurrido veinticuatro horas de la salida al mar de la 'San Carlos' ${ }^{51}$. El autor de esta breve obra que, probablemente, se basara en su momento en informaciones muy similares a las ofrecidas por La Gaceta de Amsterdam, subraya -con evidente exaltación patriótica- lo encarnizado de la lucha y el triste destino de los ingleses: heridos y capturados o fallecidos en el combate e incendio.

Sobre la identidad de una de las dos presas anteriormente realizadas por Harcksz se conserva un poder escrito un día después de su vuelta del combate con 'La Salamandra'. Este documento fue redactado a bordo del propio buque corsario, en la bahía de Cádiz:

\footnotetext{
${ }^{49}$ La Gazette d'Amsterdam, n. 26, noticia de 24 de mayo de 1665. Cornelis de Jonge menciona que tanto Douwe Harcksz -también escrito Harckz o Harcx- como Dirck Jansse Duysent eran capitanes mercantes holandeses comerciaban en el Levante- que se habrían puesto al servicio en España al estallar la guerra, para perjudicar a los ingleses (op. cit., p. 54).

50 "Naauwelycks vier en twintigh uren in zee ge weest, ontmoet Douwve Harckz, voorsien met vier er twintig stucken en hondert man, een Engels Fregat de Salamander met acht en twintig stucken van Londen, met vers volck vier hondert vaatjes buskeruid, en andere krijgsbehoeften na Tanger afghevaerdigt na een hevig gevecht van vier of vyf uyren verovert by den Engelsman: doch de brandt int Schip geraack. bleef hem niet als de vlag, den Hopman, en vystig Engelse over de andere waren of door't gevecht of door't vuir vernield". VENCKEL, Iacob: Vermeerderde, en verbeterde Engelse, Nederlandse en Munsters krackeelen, Amsterdam, 1666, p. 18.

${ }^{51}$ Cornelis de Jonge habla de 36 horas de persecución. Así mismo, señala que 'La Salamandra' disponía de 24 piezas de artillería y 100 hombres (op. cit., p. 55).
} 
“el capitán Jon (sic) Harques que lo soy de mar y guerra del nauío nombrado 'San Carlos', que con horden de los Estados Generales de Olanda, mis señores, ando por estas costas, otorgo mi poder (...) a Joseph Bredenbeque, vezino de la ciudad de Cádiz (...) en mi nombre e de los dichos Estados Generales (...) parezca ante el excelentísimo Duque de Medinaçeli, de los Consejos de Estado y Guerra de Su Magestad y Capitán General del Mar Oçéano, Costas y Exérçitos de Andaluçía (...) se declare por de buena presa a María y Graçia, esclauas negras portuguesas, que yo aprehendí en el navío que apresé çerca de los cabos nombrado 'Las Armas de Ynglaterra' de que era capitán Jorje Hermes” 52

No es este el único testimonio sobre la venta de las esclavas, aunque no se aportan más datos sobre las circunstancias de su captura ${ }^{53}$. De la otra nave apresada, sin embargo, no se ha podido encontrar registro alguno hasta la fecha. En el siguiente año, el de 1666, tampoco se le conoce a Harcksz presa alguna, aunque a la 'San Carlos' se la puede encontrar recorriendo aguas cercanas al golfo de Cádiz. Así lo indica La Gaceta de Londres en agosto:

"The two French with the 'St. Carlos', a Holland Privateer formerly in the States service at Cadiz, are returned from the Coast of Barbary and the Canary Islands without any adventure and are again falling to their trade of merchandizing." 54

En septiembre, el mismo Harcksz fletaba su embarcación para el trato de mercancías, alejándose de su actividad principal ejercida tan solo unos meses antes. En ese sentido apunta el contrato de fletamiento a unos hamburgueses para el transporte de trigo:

"Dauw Haques, de naçión olandez, estante al presente (...) como capitán y maestre que soi de la nao nonbrada 'San Carlos', que al presente está surta y anclada en la bahía (....) porte de siento y quarenta lastres (...) treinta piesas de hartillería (...) fleto la dicha nao a Bernardo Drayer y Henrique Brinque, conpañeros de la naçión hamburguesa"55

\footnotetext{
52AHPC, Protocolos Notariales de Cádiz, leg. 863, fols. 90-91, 22 de mayo de 1665.

53 “'Joseph Bredembeque, de nazión olandés, vezino (...) en nombre y en bos del capitán Bou Harquez de la dicha naçión, capitán de mar y guerra del navío ‘San Carlos' que, con orden de los Estados Generales de Olanda, anda en estas costas (...) estando a bordo del dicho su navío en la bahía (...) en veinte y dos de mayo (...) sesenta y çinco (...) se declaren por de buena presa a María y Graçia, esclauas negras portuguesas que yo aprehendí en el navío que apresé çerca de los cabos, nombrado 'Las Armas de Yngalaterra', de que era capitán Jorge Hermes". Tras la reproducción del documento anteriormente transcrito, Bredembeque procedía a la venta de María: "bendo (...) a don Joseph Vonete, vezino (...) tesorero general de las bulas della y su obispado, una esclava negra ateçada nombrada María, de hedad de doze años (...) es vna de las dos que contiene el poder ynserto (...) (que) tiene el dicho mi parte a bordo de un navío en la bahía" (AHPC, Protocolos Notariales de Cádiz, leg. 863, fols. 120-122, 16 de julio de 1666).
}

${ }^{54}$ The London Gazette, n. 90, 31 de agosto de 1666.

55AHPC, Protocolos Notariales de Cádiz, leg. 2105, fols. 192-196v, 6 de septiembre de 1666. 
Siguiendo con otros casos, una fianza del mes de diciembre de 1665 permite reconstruir los movimientos anteriores del navío holandés 'San Juan Evangelista'. Su capitán, el también holandés Pedro Enríquez, habría salido "a corzo contra sus enemigos. Y abiendo coxido en el paraje del Estrecho de Gibraltar un navío de yngleses con carga de bacallao y tavaco, y apressándole lo truxeron a esta dicha bahía" ${ }^{56}$. Tres de los soldados que iban a bordo y que participaron en la toma (Pedro Franco, Pedro de Oliveros Porsi y Francisco Moller) se encontraban en Cádiz pretendiendo que se les abonara su parte correspondiente de la presa. Esto no se había llevado a cabo aún, estando la nave y su carga en poder del comisario general de los Estados de Holanda en El Puerto de Santa María.

El navío 'La Ventura', de 45 toneladas, salió de Marsella el día 21 de marzo de 1665 con carga de jabón, algodón, goma y agallas, todas mercancías propiedad de un mercader de Nantes, a donde se dirigía. Su capitán era Juan Cole, inglés de Plymouth. Sin embargo “estando serca de la çiudad de Málaga, para entrar y dar forno en su baía, le apresó el capitán Gali Galison, holandés, que lo es del nauío 'La Judi Marchante’, con su lancha, metiéndole gente dentro" 57 . Galison carecía de patente de corso holandesa, pero condujo la presa a Cádiz el día 4 de abril. Cole denunciaba que fue obligado a firmar un papel en lengua flamenca, que no entendió, en presencia del cónsul holandés de Cádiz. Esto jugó en contra de sus intereses, dificultando la recuperación de la nave -propiedad del francés Antonio Basete- y sus mercancías.

En torno a agosto de 1666 un aventurero o corsario holandés capturaba un navío inglés que venía de Tánger ${ }^{58}$. Lamentablemente, la información dada por La Gaceta extraordinaria de Amsterdam no aportaba más datos que el destino de la tripulación de a bordo. Esta fue obligada a desembarcar en Tarifa.

Otro caso extenso e interesante fue el de 'El Mercurio', saetía armada en corso por el capitán holandés Adrián Adriansen" ${ }^{59}$ La presa del navichuelo inglés 'San Carlos' generó

\footnotetext{
${ }^{56}$ AHPC, Protocolos Notariales de Cádiz, leg. 6, fol. 472, 10 de diciembre de 1665.

${ }^{57}$ AHPC, Protocolos Notariales de Cádiz, leg. 4415, fols. 155-157r, 28 de abril de 1665.

${ }^{58}$ Noticia de Madrid de 25 de agosto de 1666, La Gazette extraordinaire d'Amsterdam, n. 23.

${ }^{59}$ Entre los documentos presentados ante notario en junio de 1666 -con el concierto del comisario de Holanda en Cádiz, Gisberto Melse- figuraban: "un pliego de papel blanco scripto a lo largo, que contiene dies renglones, y marcado a un lado con lacre y estanpado vn sello que comienssa: Capitán Adriaen Adriaenze ban Amsterdam. Y su fecha es de quatro de marzo passado deste año. Y al parezer está firmado del dicho Jisberto Melse. Y a el lado del dicho sello está rubricado de mi rúbrica. Y asímismo me entregó otro papel de pliego blanco, escripto a lo largo, que contiene dies renglones en lengua olandeza, según dijo el dicho Huberto (Borghort), y está lacrado al fin con lacre y sellado; y comiensa: Capitán Adriaen Adriaenzen ban Hastardan. Su fecha del en veynte y quatro de mayo passado de este año y firmado a el pareser del dicho Jisberto Melse y a el lado del dicho sello está rubricado de mi rúbrica. Que anbos dichos papeles tienen la fecha del dicho Puerto de Santa María, los quales pidió los zerrase y hiziese vn pliego dellos y pusiese en subre escripto papeles tocantes a Adrian Adrianze y los guardase en mi poder hasta que me los pidiese originales, dándome recibo de ellos ante scrivano por que los querrá tener guardados en poder de persona pública para guarda de su derecho" (AHPC, Protocolos
} 
decenas de documentos en los registros notariales a lo largo de varios años. Huberto Borghort o Vergost, de nación holandés ${ }^{60}$, vecino de Cádiz, era el depositario "del nauichuelo ynglés nonbrado 'San Carlos' surto en la vahía (...) de porte de ochenta toneladas con sus pertrechos, armas y aparejos, que es el mismo que apresó la saetía de guerra nonbrada 'El Mercurio', capitán Adrián Adriansen, olandés” ${ }^{61}$. En julio de 1666 se encontraba "abarratado", es decir, con las escotillas clavadas. El sargento mayor Matías Gómez Trigoso fue el encargado de conducirlo hacia el interior de la bahía, para que estuviera a la vista y no corriera peligro de mar o enemigos que pudieran sobrevenir. El 'San Carlos' había sido apresado "en el puerto de la ciudad de Sanlúcar de Varrameda y devajo de su artillería" ${ }^{2}$. El comerciante inglés Juan Duncan, actuando en su nombre y en el de otros interesados, había exigido la restitución de presa y carga, así como el abono de los gastos y daños ocasionados, pues había sido una toma en ruptura de la neutralidad del puerto. Otros poderes registrados en los protocolos gaditanos aclaran que el que iba al mando de 'El Mercurio' en el momento de la captura era el teniente Juan Carlos Dorp, y que esta se había producido bajo el rango de acción de los castillos del Espíritu Santo y San Salvador ${ }^{63}$. Adriansen, por su parte, justificaba el apresamiento:

"Adrián Adriansen, de nación olandés, residente en esta ciudad de Cádiz (...) (doy) poder cumplido (...) a Thomas Díaz, agente de negocios en los Reales Consejos y residente en la villa de Madrid (...) (por) vn pleito (...) seguido contra mí por Juan Duncan, de nación ynglés, sobre la presa que Juan Carlos Dorp, mi theniente en la saetía de guerra con que ando en corço, hiço del navío nombrado 'San Carlos' sobre la broa ${ }^{64}$ de Sanlúcar, por tocar con su carga a inglés, con quienes los Estados de Olanda tienen guerra; que por la dicha justicia se a dado sentencia contra mí declarando no ser presa legítima, de la qual tengo apelado"65

La 'San Carlos' fue asegurada por distintos residentes y vecinos de Cádiz ${ }^{66}$. Precisamente es el poder notarial de los aseguradores el que aclara que esta nao o embarcación debía realizar una ruta entre Sanlúcar y Nueva Inglaterra. Su capitán era “Jorxe

\footnotetext{
Notariales de Cádiz, leg. 2518, fol. 105, 18 de junio de 1666). Sobre 'El Mercurio', este era “de porte de ochenta toneladas, poco más o menos" (Ibídem, fols. 204-206, 15 de octubre de 1666). Al respecto del capitán Adriansen, una nave suya anterior a esta saetía, también llamada 'El Mercurio' o por otro nombre 'San Hilarión', fue fletada en 1664 para ir en conserva de la Flota de Tierra Firme. En su viaje de vuelta en 1665, en su función como patache de La Margarita, fue capturado por corsarios berberiscos.

${ }^{60}$ Aunque en algunos documentos se le identifica como alemán.

${ }^{61}$ AHPC, Protocolos Notariales de Cádiz, leg. 1796, fol. 191, 22 de julio de 1666.

${ }^{62}$ Ibidem, fol. 192, 21 de julio de 1666.

${ }^{63}$ Ibidem, fols. 254 y 262, 25 de octubre y 19 de noviembre de 1666. En este último 'El Mercurio' es definido como fragata de corso.

${ }^{64}$ Abra o ensenada llena de barras y rompientes (Diccionario de la Real Academia Española).

${ }^{65}$ AHPC, Protocolos Notariales de Cádiz, leg. 2518, fol. 190, 2 de octubre de 1666.

${ }^{66}$ Concretamente "Jaques Filter, Gutiérres Mahuns, Thomas Pridan y (tachado: Daniel Merzier) Diego Maestre, Gaspar Pluyms, don Alexandro Xacome de Linden, Gabriel Muys y Juan Haçenjen" (AHPC, Protocolos Notariales de Cádiz, leg. 1797, fols. 1-2r, 6 de octubre de 1666).
} 
de Lahydd", y en seguimiento de su viaje "fue apresada con las mercadurías que traýa, por unas naos de corso de Olanda, como es público y notorio"67. Juan Carlos Dorp ofreció otra versión de los hechos, argumentando que la captura se produjo en el contexto de la guerra entre Inglaterra y las Provincias Unidas de Holanda. Además, el lugar de la toma era precisado -convenientemente- algo más alejado de Sanlúcar, para evitar la violación de su seguro:

“yo, Juan Carlos Dorp, de naçión olandés, estante en esta çiudad de Cádiz, theniente de la saetía de guerra nonbrada 'El Mercurio', capitán Adrián Adriansen, de mi misma naçión, que (...) con patentes lexítimas y cauo que (soy) (...) del dicho capitán, por lo que me toca como tal theniente (...) estando la dicha saetía a mi cargo o yo en ella como prinçipal, nabegando en alta mar, apresé en el paraje de [Arenas] Gordas ${ }^{68}$ vn nabichuelo ynglés perteneçiente con su carga" ${ }^{6} 9$

La sentencia fue contraria a los intereses de los corsistas. Sin embargo, se procedió a la venta del barco y su carga en beneficio de Juan Duncan. El 'San Carlos' era un navío de porte de 80 toneladas y llevaba a bordo aceite, vino, pasas y almendras, entre otras mercancías de menor entidad. Se pagó por todo ello 14.000 reales de plata. El registro de su pregón, inventario y subasta pública quizás sea uno de los documentos más interesantes de todos los analizados en este artículo, pues muy pocas veces se conserva tal tipología documental en los archivos. Este, de hecho, está anexado justo al principio del volumen de escrituras emitidas por el gaditano Juan Rodríguez de Medinilla, fuera de su índice y desarrollo habitual ${ }^{70}$.

En octubre de 1666, Adriansen procedió a la venta de la que fuera su saetía de corso a un capitán llamado Enrique Col, vecino de Cádiz ${ }^{71}$. Curiosamente, este Col era otro corsario que actuaba con patente francesa. Aprovechó el conflicto para llevar a cabo su propia campaña. En abril de 1667, Col procedió a vender un navío pingue inglés de fábrica holandesa, de porte de unas 60 toneladas ${ }^{72}$, que había apresado el día 3 de febrero en la costa de Sancti Petri, llevando a su cargo el 'San Luis', con patente del Duque de Bofors ${ }^{73}$. Los

\footnotetext{
${ }^{67}$ Jorge de Lahid o Lahydr era inglés (Ibídem, fols. 9-12, 2 de enero de 1667).

68 Zona de la costa onubense en la otra banda del Guadalquivir.

${ }^{69}$ AHPC, Protocolos Notariales de Cádiz, leg. 738, s. fol, 19 de julio de 1666.

${ }^{70}$ Se remite al apéndice para su lectura. Obsérvese que quedan reflejadas frases textuales del pregón y subasta, con los usos habituales en este tipo de comunicaciones para captar la atención del público.

71 “yo, el capitán Adrián Adriansen, de nasión olandés, recidente (sic) en esta ciudad de Cádiz, por mí y en nombre de mis herederos otorgo que vendo y hago venta real desde oy para siempre xamás al capitán Henrrique Col, vecino de esta dicha ciudad, que está presente, para el sussodicho y sus herederos o las demás perssonas que por qualquier título, caussa o rassón que sea lo tengan, a saber: vna saetía propia mía, nombrada 'El Mercurio', que está surta y anclada en la bahía de esta dicha ciudad" (AHPC, Protocolos Notariales de Cádiz , leg. 2518, fols. 204-206, 15 de octubre de 1666).

$72 \mathrm{El}$ documento no se encuentra en buen estado y el nombre es difícil de discernir "La Tanr[...]ina" (AHPC, Protocolos Notariales de Cádiz, leg. 738, s. fol, 28 de abril de 1667). Se vendió en precio de 1.600 pesos.

${ }^{73}$ Seguramente el Duque de Beaufort, General de la Armada Real de Francia.
} 
armadores de la nave corsaria eran "Vberto Burgost, Giles Ama y Juan Ye[...], [hom]bres de negoçios en esta dicha çiudad (de Cádiz)"74. La fianza indicaba que habrían sido partícipes de las presas que había hecho contra ingleses. En una de sus salidas habría:

"seguido un navío sobre esta costa, por no haver querido aguardar al llamado que le hiço; y por considerarlos enemigos le siguió. El qual por escaparse huyendo varó en la playa de Nuestra Señora de Reglas ${ }^{75}$, por cuya raçón Antonio Colin, de naçión flamenco, capitán y maestre del dicho navío barado, ante la justiçia desta dicha çiudad, por presençia de Antonio Ximénez, cauallero escrivano deste número, dio querella criminal contra el dicho capitán Henrique Col, pidiéndole restituyese el valor de la dicha carga y navío"

La sentencia fijó la condena de Col en el pago de 700 pesos por el daño que había causado en barco y carga. El propietario de estos era Guillermo Harinque o Gerinsx, hombre de negocios y vecino de Amberes. Es otro testimonio el que permite clarificar las circunstancias. Se trata del poder de cobro utilizado por otro hombre de negocios holandés en representación de Harinque. En él se indica que se habían realizado autos ante el escribano de número de Cádiz, Juan Núñez Rasero, a causa de que el capitán Enrique Col y su saetía de corso andaban en las costas españolas con patente del Rey de Francia:

"sobre la pérdida del navío nombrado 'La Paz', de que fue capitán y maestre Antonio Colen (...) con el dicho su navío nombrado 'La Paz' a estos reynos de Castilla por el mes de noviembre del dicho año pasado de seissientos y sesenta y seis, hallándose sobre la broa de la ciudad de Sanlúcar de Barrameda, de término pasar a la vahía desta dicha ciudad; y desde que se apartó de la dicha broa lo vino siguiendo y dando casa la dicha saetía de corso (...) y huyendo della el dicho Antonio Colen baró con el dicho su navío en la playa de Nuestra Señora de Regla, a donde se hiso pedasos y salió la carga de duelas ${ }^{76}$ que traýa"77

\footnotetext{
${ }^{74}$ AHPC, Protocolos Notariales de Cádiz, leg. 738, s. fol, abril de 1667.

${ }^{75}$ En Chipiona.

76 Tablas que forman las paredes curvas de las pipas, cubas, barriles, etc. (DRAE).

${ }_{77}^{7}$ AHPC, Protocolos Notariales de Cádiz, leg. 2352, fols. 294-295, 29 de marzo de 1667. Otra narración, con nuevos datos, puede hallarse en la declaración de Gisberto Vanquesel: “de Amburgo salió la nao nombrada 'La Paz', de que es capitán Antonio Col, cargada de duelas y otras mercadurías; dirigido su viaxe a la bahía desta ciudad, consignada su carga a mí, como correspondiente de quien la cargó, y siendo como es el dicho capitán flamenco ostendés; y que en la dicha nao traýa bandera de Borg[oña]. Vn cosario que anda con vna nao com (sic) bandera y patentes de Françia los acossó, de forma que la hiço barar en la costa de Chipiona, donde se perdió. Y demás dello el dicho cosario la robó” (AHPC, Protocolos Notariales de Cádiz, leg. 5721, fols. 268269, 27 de noviembre de 1666). El mismo Antonio Colen, de Ostende, otorgó poder a Daniel y a Andrés Haquer, hermanos con una compañía comercial, para proseguir el pleito contra "Enrique Col, capitán de la saetía de corso que anda en estas costas con patente de Françia y de los demás armadores y marineros de la dicha saetía”. Fija el varamiento diez y siete días antes de la data (AHPC, Protocolos Notariales de Cádiz, leg. 2351, fol. 715, 5 de diciembre de 1666). Véase también la carta de pago a la tripulación (cocinero, contramaestre, piloto y muchacho) que le ayudaron a recoger parte de la carga de la playa (Ibídem, fol. 716, 6 de diciembre de 1666).
} 
Enrique Col probablemente fuera el Enrique Escol que figura en otros documentos de 1665 como capitán del navío 'San Antonio de Padua', también relacionado con el negociante Huberto Borghort ${ }^{78}$. En cualquier caso, en la declaración del capitán de 'La Paz' se especifica que la nave era de porte de 140 toneladas y que llevaba a bordo siete marineros y un paje. El día 18 de noviembre de 1666 trató de entrar en la barra de Cádiz y:

"por parezerle que una saetía pequeña que parezía tartana que staua por la banda de afuera andaua pescando, y auiendo virado para venir en derechura a esta dicha çiudad, esta dicha saetía le vino dando caza, disparando munchas cargas de artillería. Y considerando que podían ser turcos o portugueses, por escapar con la uidas (sic), viéndose sin otro remedio, bararon con el dicho nauío en la plaia de Nuestra Señora de Regla, el dicho día, como a las doze dél. Y todos saltaron en tierra en el vote, sin sacar del dicho nauío más de sus cuerpos. Y la gente de la dicha saetía y de vn barcoluengo de su conserua entraron en él y le robaron y lleuaron la ropa de todos y del otorgante, y todas las demás cosas" 79

A pesar de que Colen y los suyos les interpelaron que no tomasen nada, ya que eran vasallos del Rey de España, los franceses procedieron a abrir la bodega del navío al día siguiente, por la noche ${ }^{80}$. Como es habitual en estos asuntos, las informaciones se muestran poco clarificadoras o vagas, al no incluir demasiados detalles.

Muchos de los casos estudiados en estas páginas adolecen de falta de datos sobre las circunstancias de la captura. Así, el 14 de febrero de 1667 se informaba desde Amsterdam que la 'Gertrudis' que volvía de Cádiz había sido apresada por los ingleses y llevada a Plymouth $^{81}$. También, en marzo de 1667, Diego Ocón, vecino de Málaga, otorgaba poder a Miguel Vangrungien, holandés avecindado en Cádiz. Debía proseguir el pleito iniciado contra el también holandés Lalanda Vis, capitán del navío 'La Reina'. Le debía 400 pesos de plata en que valoraba las mercancías que Ocón “tenía en vn nauío que apresó en la vaýa de Alicante"

\footnotetext{
${ }^{78}$ Se conservan dos documentos al respecto de una caja o balote de olanes (volantes o tiras de tela de adorno) que fue entregada por un vecino de Amsterdam al capitán Enrique Escol, dueño del navío 'San Antonio de Padua'. Debía entregarse en Cádiz a Borghort. Sin embargo, el capitán continuó viaje a Levante y a la vuelta, a pesar de que declaró haber encomendado a un barquero que hiciera el recado, Escol fue apresado por las autoridades de Cádiz, ya que llegaron noticias de que los olanes estaban en Génova. Escol fue liberado bajo fianza y parece ser que los holandeses fueron finalmente hallados a bordo de un navío anclado en la bahía (AHPC, Protocolos Notariales de Cádiz, leg. 1538, fols. 115 y 198-199, 13 de mayo y 5 de septiembre de 1665). Sin embargo, en una carta de pago de 1667 aparece un capitán Enrique Col, de nación alemán, natural de Lubeck y avecindado en Cádiz. Su apellido original sería Kol o Kollen (AHPC, PNC, leg. 5722, fols. 103 y ss.). ${ }^{79}$ AHPC, Protocolos Notariales de Cádiz, leg. 2351, fols. 740-741, 16 de diciembre de 1666.

${ }^{80} \mathrm{El}$ buque fue comprado en 8.000 florines flamencos. Otros documentos relacionados con el caso: AHPC, Protocolos Notariales de Cádiz, leg. 5722, fols. 9 y 111, 24 y 28 de marzo de 1667. En este último testimonio, se identifica el lugar del varamiento como Salmedina, y califica a Col como pirata: "que se perdió acosado de otro en el término de la uilla de Rota, en el sitio que dizen Salmerina (sic); y para que por todas las maneras que fuere posible, pueda perseguir al pirata que hechó al dicho nabío a tierra”.

${ }^{81}$ Gazette ordinaire d'Amsterdam, 14 de febrero de 1667. Al parecer, el comandante Ulpert se habría hecho con dos barcos holandeses y dos franceses partidos de Cádiz para Saint-Malo, pero por tormenta solo había podido llevar una de las presas a Plymouth. Las otras fueron lanzadas sobre las costas de Irlanda. 82AHPC, Protocolos Notariales de Cádiz, leg. 864, fol. 93, 21 de marzo de 1667.
} 
Otros casos, en cambio, pueden reconstruirse gracias a múltiples fuentes e, incluso, puntos de vista contrarios. El 24 de febrero de 1667 los contactos de La Gaceta ordinaria de Amsterdam en Madrid enviaban noticia de que una nave armada por zelandeses se habría enfrentado a la vista de Cádiz con una fragata inglesa más grande y mejor armada, aunque no hubo apresamiento, ya que los ingleses se retiraron al puerto, bajo la protección de la artillería de la ciudad ${ }^{83}$. Será otra noticia, de unos días más tarde y de La Gaceta de Londres, la que permita dilucidar los hechos ${ }^{84}$. La fragata inglesa era la 'Pembroke', y su capitán Arthur Herbert. El 6 de marzo volvía a encontrarse en Cádiz tras una nueva lucha con la nave zelandesa, un buque de guerra de 34 cañones y 180 hombres. El combate comenzó a las dos de la tarde y, a la caída de la noche, hubo tregua. Se reanudó al amanecer, aunque parece que el zelandés evitó la confrontación directa. La fragata inglesa retornó a puerto, donde se procedió a su reparación. Aunque el zelandés buscó desafiarlo de nuevo, no fue hasta el día 5 por la mañana cuando se materializó un nuevo envite. La fragata inglesa estaba ya lista y salió a su encuentro. La nave zelandesa estuvo cinco veces a tiro de pistola de la otra, resultando varios hombres muertos y heridos -al menos en la cubierta inglesa-. La persecución consiguiente fue infructuosa y se produjo un intercambio de disparos a modo de reto.

El 'Pembroke’ quedó en el mar mientras que el zelandés retornó a puerto. La Gaceta de Londres - quizás imbuída del afán propagandístico de la prensa del momento- aludía a que el capitán zelandés había pretendido hacer ver a todos que tal parada era obligada, debido a la necesidad de reparar el palo mayor, así como para reabastecerse de munición.

La Gaceta ordinaria de Amsterdam volvería a recoger nuevas de Cádiz fechadas el 13 de marzo $^{85}$. Entre ellas se habla de una fragata inglesa que habría apresado dos naves, la 'Santa Catalina’ y el ‘Águila Blanca ${ }^{86}$. También de otra embarcación de Inglaterra que habría luchado en aguas del cabo de San Vicente con un navío armado de Zelanda. La primera se vió obligada a huir y refugiarse en Cádiz, tras haber perdido a su capitán y una docena de hombres. No parece factible que se tratara de la 'Pembroke', pues Herbert seguía vivo entonces. Al margen de estas informaciones, la noticia sigue con la mención a otra nave zelandesa que se habría batido con una fragata inglesa a la vista de Cádiz. Esta referencia sí que podría responder al suceso, teniendo algunos puntos comunes con lo explicitado en el periódico londinense. Al mando de la embarcación zelandesa iba el capitán Backer, y la nave había sido

\footnotetext{
${ }^{83}$ Gazette ordinaire d'Amsterdam, 28 de marzo de 1667.

84 The London Gazette, n. 143.

${ }^{85}$ Gazette ordinaire d'Amsterdam, 18 de abril de 1667.

86 Traducción aproximada.
} 
armada en corso. Partiendo de Cádiz, topó con dos naves turcas en la embocadura del Estrecho de Gibraltar. Recibió grandes daños en su mástil y, necesitado además de municiones, retornó a la bahía. A la vista del puerto gaditano fue interceptada por una fragata inglesa de 34 piezas de artillería. Se deduce de las confusas líneas que narran la sucesión de hechos que, tras un primer combate en el que la fragata inglesa se vio obligada a refugiarse en puerto, hubo oportunidad de otra confrontación. En esta ocasión es la prensa holandesa la que exhibe orgullo patriótico al aseverar que fue un acto honorable para ofrecer al capitán inglés la oportunidad de restituir su honor. El zelandés, sin munición, intentó el abordaje -de ahí que pasara varias veces a distancia de pistola de la otra nave-, sin embargo, la fragata volvió a retirarse a Cádiz.

La Gaceta ordinaria de Amsterdam continuaría refiriendo, el 21 de marzo, que una nave armada zelandesa entabló combate con otra inglesa, luchando durante varias horas en la bahía $^{87}$. Cifra las pérdidas totales en diecisiete tripulantes para la embarcación inglesa, mientras que solo tres para la zelandesa.

El armador corsario zelandés aludido era Joris Backer y su nave, la fragata 'El Príncipe Guillermo III'. Disponía esta de 30 piezas de artillería y 150 hombres. La 'Pembroke', por el contrario, contaba con los ya mencionados 34 cañones y 200 tripulantes $^{88}$. Herbert, primer Conde de Torrington, había llegado a la capitanía de la 'Pembroke' en 1666. Herbert volvió tras su lance en aguas gaditanas a Inglaterra, integrado en un convoy ${ }^{89}$, aunque en las cercanías de la isla de Portland perdió el barco por una maniobra desafortunada con otro navío de guerra $^{90}$. El holandés Backer, por otra parte, siguió actuando en el Estrecho con éxito:

"L’on a avis du Detroit que le capitaine Juariaen Backer, qui s'est si bien batu devant Cadix contre une Fregate Angloise, a pris \& envoyé au Texel par derriere l'Escoss un vaisseau Anglois venant des Virginies avec 700 barils de Tabac" 91

\footnotetext{
${ }^{87}$ Gazette ordinaire d'Amsterdam, 21 de marzo de 1667. Entiéndase que estas informaciones llegaban tardíamente desde lugares lejanos, de ahí que esté en un número anterior de dicha gaceta.

88 "Un armateur hollandois, Joris Backer estant avec sa fregatte le Prins William III montée de 30 pieces \& 150 hommes, dans la Baye de Cadix presentat le combar a un vaisseau convoy anglois le Penbroock monté de 34 pieces \& 200 hommes \&o se combattoint plus de 4 heures, quand l'anglou (sic) craindant d'estre abordé par l'hollandois se desmele eo le mit sous le canon du chasteau (sic) ou il fut mocqué des espagnols ol avoit receu 17 morts \& l'bollandois 3". BENJAMIN, Jacques: Description exacte de tout ce qui s'est passé dans les guerres entre le roy d'Angleterre, le roy de France, les Estats des Provinces Unies du Paysbas et l'evesque de Munster, Amsterdam, 1668, p. 211.

${ }^{89}$ Bajo el mando del Contraalmirante Kempthorne. Véase la noticia de 4 de abril de The London Gazette, n. 151.

${ }^{90} \mathrm{La}$ historiografía tradicional inglesa reseña que no fue culpa suya, y que prueba de ello fue que pronto volvió a ser comisionado, convirtiéndose en Comandante en Jefe del Mediterráneo y Vicealmirante. El combate en Cádiz es narrado con un cierto tono laudatorio, lejos de cualquier tipo de crítica. Véanse, entre otros: "Memoirs of Arthur Herbert", en CAMPBELL, John: Lives of the British admirals: containing a new and accurate naval history from the earliest periods, Londres, vol. II, 1785; "Naval Officers of Great Britain" en CHARNOCK, John: Biographia Navalis, Londres, vol. I, 1794, pp. 258 y ss.; "English Admirals during the Revolution, 1688: Herbert (earl of Torrington)", en The Court and Lady's Magazine, junio de 1845.

${ }^{91}$ Gazette ordinaire d'Amsterdam, 13 de junio de 1667.
} 
En Cádiz hay registro de un poder, finalmente no otorgado, donde podría reflejarse esta presa u otra muy cercana en el tiempo. Había sido redactado a instancia del holandés Dique Piter Scap para que Guillermo Backer, residente en dicha ciudad, cobrara 275 pesos de plata "que restó deuiendo del valor del nauío de presa que le vendí y antes compré de Jorje Gerardo Baquer, capitán del nauío de corço nombrado 'El Prínçipe" ${ }^{92}$.

Incluso tras la firma de las paces entre Inglaterra y Holanda, los corsarios flamencos continuaron navegando las aguas del golfo de Cádiz ${ }^{93}$. En enero de 1668 se registraba un poder otorgado por Juan Frans, flamenco avecindado en Vigo, que residía por entonces en Cádiz ${ }^{94}$. Él y otros convecinos armadores disponían de un navío llamado 'Santiago', del cual Frans era capitán, poseyendo patente del Rey de España para ir contra enemigos de la Corona. También, ese mismo día se otorgó otro poder por parte de Juan Osten, vecino de Ostende, con patente de capitán corsario de la nave nombrada 'San Antonio', también de armadores de Vigo ${ }^{95}$.

Al contrario que para los holandeses, no existen muchos testimonios de corsarios ingleses que operasen en Cádiz o sus alrededores. Es entendible debido a la alianza entre Inglaterra y Portugal, en rebeldía a la Corona de España para recuperar su independencia. Al principio de la guerra, en 1665, el inglés establecido en Cádiz Samuel Carington poseía patente de corso para actuar con más de una nave ${ }^{96}$. Así lo indicaba la fianza otorgada por Esteban Ramírez y Pedro Muñoz, vecinos de Cádiz: “por quanto el capitán don Samuel Carington, entretenido en la Armada Real del Mar Oçéano, tiene lisençia de Su Magestad para salir a corso (...) (con) el bergantín que llaman barco luengo nombrado 'Nuestra Señora de Regla', que es la envarcaçión más próxima que tiene para salir en corso"97. La nave había sido vendida por un vecino de El Puerto de Santa María, el capitán Guillermo Baquer, como se confirmaba en documento fechado en diciembre del mencionado año:

\footnotetext{
92AHPC, Protocolos Notariales de Cádiz, leg. 864, fol. 90, 16 de marzo de 1667.

${ }^{93}$ El historiador Otero Lana destaca de su actuación entre 1660 y 1668 que los flamencos podían ser especialmente díscolos en el ejercicio del corso, llevando a cabo estrategias o tácticas destinadas no tanto a salvaguardar la corrección del proceso como a garantizar la obtención de beneficio (op. cit., p. 318).

${ }^{94}$ AHPC, Protocolos Notariales de Cádiz, leg. 864, fol. 378, 10 de enero de 1668.

${ }^{95}$ Ibidem, fol. 379.

${ }^{96}$ En 1665 Carington actuaba como intermediario en el embargo de las mercancías y venta del navío 'Santa Catalina', del capitán inglés Thomas Covel: “un navío pingue nombrado 'Santa Catalina' que está surto en la bahía $(. .$.$) de porte de ochenta toneles (...) con todos los peltrechos, artillería, velas, árboles, vergas, harçia,$ chalupa, cables, anclas y demás aparexos (...) el qual lo hubo y compró de el capitán don Samuel Carinton, en nombre del capitán Thomas Covel, cuyo hera" (1 y 2 de julio, AHPC, Protocolos Notariales de Cádiz, leg. 6, fols. 249-251, 273-274, 440-442, 19 de octubre de 1665). Abraham Lee, vecino de El Puerto de Santa María tenía una deuda con Covel y este, a su vez, con Carington. Por ello se embargó el pingue y su carga. Finalmente fue comprado por Thomas Tase, francés de Saint-Malo, por 16.400 reales. Otero Lana sitúa a Carington como armador corsario en Livorno (Italia) en 1657 (op. cit., p. 430).

${ }^{97}$ AHPC, Protocolos Notariales de Cádiz, leg. 1796, fol. 104, 19 de septiembre de 1665.
} 
"un barco longo con cubierta, que es forma de vergantín, de porte de dies y ocho bancos, nonbrado 'Nuestra Señora de Regla', que es el mesmo que de presente está [ancl]ado en la playa desta dicha ciudad debajo de las murallas della, entre las dos puertas de la mar y Seuilla"98

La patente de corso habría sido refrendada en Madrid, el 6 de noviembre, figurando que sería para "andar en corsso contra enemigos y rebeldes de la Real Corona en el vergantín nombrado 'Nuestra Señora de Regla', corriendo las costas de Portugal, Berbería y todas las demás de España Ytalia (sic) pelear y apresar todos los bajeles que vieren de enemigos y rebeldes" $"$ ".

A finales de 1666 Carington dejaba hecho testamento en Cádiz, en el cual se indica su título como capitán reformado de la Real Armada y Ejército del Mar Océano, así como la propiedad del bergantín o barcoluengo 'Nuestra Señora de Regla'. El por qué de testar entonces lo señalaba a continuación: “estoy de prósimo para salir a navegar a corsso, con patente de Su Magestad Católica, contra sus enemigos, reveldes a su Real Corona" ${ }^{100}$. Nada indica de su posible campaña previa ${ }^{101}$, pero sí de las condiciones con las que saldría a navegar en esta ocasión:

\footnotetext{
${ }^{98} \mathrm{AHPC}$, Protocolos Notariales de Cádiz, leg. 737, fols. 226-227, 19 de diciembre de 1665.

${ }^{99}$ La nave había sido contruida a instancia de Backer. El capitán Nicolás Casier, residente en Cádiz, lo había comprado por 900 pesos (AHPC, Protocolos Notariales de Cádiz, leg. 737, fols. 228-230, 19-21 de diciembre de 1665).

${ }^{100}$ AHPC, Protocolos Notariales de Cádiz, leg. 738, fols. 211-213, 20 de octubre a 15 de noviembre de 1666. Carington era "hijo lexítimo de don Antonio Carington y doña Ysavel Carington, mis padres difuntos, vezinos y naturales que fueron de la ciudad de Londres, en el reino de Yngalaterra (...) fui casado de primero matrimonio [...] lugar de Ipsvich, en el dicho reino de Ynglaterra [...] con doña Francisca Eldret, hixa lexítima de don Ran[...] y doña Francisca Eldret, sus padres, vezinos del dicho lugar [...] la qual es difunta. Y en el discurso de diez añ $[o s][\ldots]$ duró el dicho matrimonio, ubimos y procreamos [...] por nuestra hixa lexítima nonbrada doña Francisca Cha[...] que oy bive en el dicho lugar con sus abuelos (...) onçe de junio del año pasado de mill y seiscientos y sesenta y tres casé de segundo matrimonio en la villa de Madrid con doña Raphaela Ortíz y Bibanco, natural de la villa de Consuegra, en La Mancha (...) Respecto de haber muerto, en esta [...] la dicha doña Raphaela, mi muxer, en la qual no tube hijos ninguno".

${ }^{101}$ En documento de mayo de 1666, el inglés "Samuel Estaf", contramaestre entonces de 'La Tunecina', reclamaba su soldada al haber servido "en el vergantín de corso [...] capitán Samuel Carington" (AHPC, PNC, leg. 738, s. fol). Sobre sus acciones, un testimonio conservado en los protocolos notariales onubenses apunta en la dirección de que llegara a realizar incursiones en tierra, pues años más tarde se reclamó la liberación de unos cautivos por parte de: "el alférez Alonso Pérez Rangel, vecino de esta dicha villa, y Sebastián Villegas, de color moreno, de nación portuguesa, vezino de Caçela, en el Algarve, Reyno de Portugal. Y dixeron que el capitán Don Samuel Carigton (sic), ynglés, ressidente de la ciudad de cádiz, que andava corseando en estas costas con su vergantín, apresó en el dicho reyno, en el campo de la dicha villa de Caçela, por el año passado de mill y seiscientos y sesenta y seis, a Bárbara Fernández, muger de dicho Sebastián Villegas, y a Lorenço Antonio María y una niña, María, que era de pecho, todos hijos del dicho (...) suponiendo ser todos esclavos captivos (...) los vendió dicho capitán en esta villa" (Archivo Histórico de Protocolos de Huelva (A.H.P.H), Protocolos Notariales de Huelva, leg. 4727, fol. 75-76, 15 de febrero de 1669). En cuanto al lugar, se trataría de Cacela Velha, en el municipio de Vila Real de Santo António.
} 
"de presente estoy para salir a nabegar, como queda referido, a corso contra enemigos y rebeldes a la Corona Real de Su Magestad Cathólica, con el dicho bergantín. En el qual llebo enbarcados, sin mi persona, quarenta hombres con el sustento neçesario para dos meses. Y es [...] pagado y lastra de mi propio caudal en pertrechos, carenas, muniçiones, bastimentos $[\ldots]$ y lo demás necesario, más de tres mill pesos, que e de haver y cobrar de las presas que con él hiçiere, sin las porçiones lexítimas que hubiere de haver dellas”"102

En abril de 1665 Juan Duncan otorgaba poder a Pedro de Rojo, comerciante flamenco vecino de La Laguna (Tenerife), para que continuara pleito contra los herederos de Thomas Borases. Les exigía 2.000 reales de plata por los gastos que realizó este en la defensa para que se declarase mala presa, y por tanto libre, el navío 'La Rosa': “que viniendo de Terranoba con bacallao fue apresado por vn nauío pechelingue nonbrado 'Thomas Elders' y peteneçía al dicho difunto" ${ }^{\text {103 }}$. Parece factible que el navío pirata fuera inglés ${ }^{104}$.

El corso inglés tenía como una de sus bases de operaciones el norte de África. En la Gaceta de Amsterdam de 5 agosto de 1666 se narraban las acciones de una galeota inglesa en la bahía de Cádi $z^{105}$. Esta embarcación venida de Tánger había atacado a dos navíos holandeses en la zona en la que fondeaban las naves, con la pretensión de apresarlas. Al no conseguirlo, intentó apoderarse de una pequeña embarcación francesa, que no tenía medio de oponerse con éxito. Sin embargo, la tripulación prefirió "se jetter en côte \& se bruler soi-méme, que de tomer entre ses mains". Como consecuencia, por lo que era calificado como una grave falta de respeto a la neutralidad del puerto, el cónsul inglés fue hecho prisionero.

Juan Jaime de Blanes, catalán residente en Cádiz, otorgó poder en marzo de 1667 para que George Walles (Jorge Valles/Guales), hombre de negocios inglés, le representara ante el Almirantazgo de Inglaterra en el pleito pendiente en la plaza de Tánger sobre habérsele “apresado la saetía nombrada 'Santa Catalina', con carga de vn mi[l] y sesenta y dos fanegas de trigo" ${ }^{106}$. Argumentaba que el apresamiento había sido injusto debido a las paces establecidas entre España e Inglaterra, pues habían sido súbditos ingleses quienes habían realizado la toma. En Tánger se procedió a la reventa de la saetía, pagando por ella Blanes 307 pesos.

\footnotetext{
102 Además: “Jiles Ammia y Roberto de (en blanco) me an socorrido con mill y quinientos pesos para ayudarme con ellos a comprar los vastimentos neçesarios para la xente de dicho bergantín, pertrechos, armas, jarçia, muniçiones y otras cosas preçisas. De la qual cantidad los susosdichos (sic) an de [ha]ber y cobrar de las presas que yo hiçiere con dicho bergantín y jente, del que así lo tengo ajustado y contenido con los susodichos". ${ }^{103}$ AHPC, Protocolos Notariales de Cádiz, leg. 1425, fol. 474, 22 de abril de 1665.

104 Sobre la interpretación de la palabra pechelingue, actualmente aceptada como sinónimo de pirata, no parece que haya un acuerdo unánime. Algunas teorías señalan su identificación con determinadas nacionalidades como la holandesa o la inglesa.

105 Noticia de Cádiz, 4 de julio de 1666, La Gazette d'Amsterdam, n. 13.

${ }^{106}$ AHPC, Protocolos Notariales de Cádiz, leg. 1425, fol. 416, 21 de marzo de 1667.
} 


\section{El período final de la Guerra de Restauración Portuguesa}

La Guerra de Restauración Portuguesa, iniciada en 1640 y que se dilataría hasta febrero de 1668, culminaría con la independencia de Portugal. En el período final de esta, coincidente con la Segunda Guerra Anglo-Neerlandesa, Inglaterra fue aliada de los lusos en la contienda contra la Monarquía Hispánica. El caso explicado en las siguientes líneas es muy interesante debido a su singularidad, ejemplificando la amplia variedad de circunstancias que rodeaban a los apresamientos de embarcaciones. A finales de 1665 , un navío corsario entraba en la bahía de Cádiz. Su tripulación se había amotinado y había conducido la nave al mencionado puerto, entregándoselo a las autoridades. Tal hecho es conocido gracias a diversos poderes concedidos por los marineros y oficiales de la embarcación, que debían cobrar un premio o recompensa por el servicio prestado a la Corona de España. El primero de los documentos conocidos es el del marinero de Amsterdam Pablos Adamis, que en febrero se encontraba ya enrolado en la nave 'El Patriarca Isaac', la cual partía teniendo como destino Cagliari (Cerdeña):

"como marinero que fuy del navío nonbrado 'San Antonio de Portugal', que se levantó y la gente dél lo entregó en esta vahía a Su Magestad y Señores Ministros de su Real Armada (...) por razón de la adeala ${ }^{107}$ o premio que se les ofreció a los ofiziales y gente del dicho navío 'San Antonio de Portugal' para mí como uno de sus marineros hubiere de haver"108

El nombre de la embarcación aparece en otros documentos desarrollado como 'San Antonio de Padua', aunque se certifica en otros testimonios que la nave era de fábrica portuguesa. Así se entiende el servicio prestado a la Real Armada Española, entregando una embarcación enemiga como captura. Otros registros notariales aportan información relevante sobre el armamento en corso de la nave y la identidad de su capitán:

"Joseph Ziuila de n[a]z[ión] f[ranzés], vezino de Santropé, en Françia, residente en esta çiudad de Cádiz, ayudante de piloto que fui del nauío de guerra nombrado 'San Antonio de Padua', que le traía en corso a su cargo el cauallero que comúnmente llamaban 'el Maltés' y vno de los tres motores y cabos prinçipales para traer co[mo] efectiuamente se trujo el dicho su nauío al seruiçio y orden de Su Magestad que Dios guarde que entró en esta vaía abrá seis meses con poca diferenzia y se agregó a la Real Armada (...) donde está siruiendo" 109

\footnotetext{
107 Adehala: aquello que se agrega de gajes o emolumentos al sueldo de algún empleo o comisión (DRAE). ${ }^{108}$ AHPC Protocolos Notariales de Cádiz, leg. 3554, fol. 46, 4 de febrero de 1666.

${ }^{109}$ Ibidem, fol. 228, 22 de mayo de 1666.
} 
Como señalaba Pedro Regidor, marinero francés de la 'San Antonio', la nave “andaba pirateando en estas co[stas]" ${ }^{\prime 10}$. La tripulación conjugaba todo tipo de nacionalidades. Otros miembros de esta fueron Juan Manu, marinero francés; Nuel Amiel, artillero francés; Miguel Amier, marinero de Ragusa (Italia); Arnao Deles, marinero de Saboya (Italia), y Bautista Chacón, pañolero de jarcia francés ${ }^{111}$. Otro poder da cuenta de Antonio Francisco y Francisco Zenes, marineros de Lisboa, y de otro francés llamado Vallen ${ }^{112}$.También iban a bordo los marineros Honorato Louchero, de Niza, y Luis Rama, de Toulon ${ }^{113}$. El piloto era inglés, y gracias a él se conocen más detalles sobre 'el Maltés' y su fragata:

"Eduardo Venmoth, de nación ynglés, natural del Condado de Cune[r]al, quatro leguas distante de la Puerta de $[\mathrm{H}]$ ogh, en el reyno de [In]galaterra, hij[o] legítimo del capitán Juan Venmoth y Juana Venmoth (...) hallándome grauado de enfermedad (...) que yo fui pilotto de la fragat[a] nombrada 'San Antonio' de que fue capittán [Mon]sieur de Plussi, cauallero de la horden de $[. .$.$] que se fabricó en el río de Lisuoa, y en que andaua en corsso$ con patente de apresción en estas costas; a la qual yo y otras perssona[s] conduzimos re[n]di[d]a y la entramos en la vahía de esta ziudad por vno de los días del mes de n[ouie]mbre passado de mil y seiscientos y sessenta y cinco"114

Un testamento permite terminar de dibujar el cuadro de estos sucesos. El francés Juan Beo testó en Cádiz en noviembre de 1665 debido a una grave herida que le mantenía en la cama. Declaró que:

"fuy theniente de condestable del nauío de guerra nombrado 'San Antonio', de quien fue capitán el Caballero del Plesi, de la horden de Malta, que hera corsante del tirano rebelde de Portugal. Y abiendo salido de puerto de Cascaes, tiempo de tres semanas, quedándose en tierra el dicho capitán, yo y otros cabos y marineros del dicho nabío nos lebantamos con él, y de la refriega con la ynfantería portuguesa de su guarnizión salí herido de la herida de que estoy curándome. Y lo trajimos y entramos en la bahía desta çiudad. Y lo entregamos al señor don Diego de Ybarra, Almirante General de la Real Armada del Mar Ozéano, trayendo rendido y debajo de escotilla más de cient ynfantes portugueses"115

\footnotetext{
${ }^{110}$ AHPC, Protocolos Notariales de Cádiz, leg. 738, s. fol, 19 de abril de 1667.

${ }^{111}$ Ibídem, 21 de junio de 1666.

112 "Antonio Francisco, natural de la ciudad de Lisboa, marinero que fui de la fragata nombrada 'San Antonio'; Francisco Zenes, natural de la dicha ciudad, marinero; Vallen [...] de nazión françés, marinero, todos tres residentes en esta ciudad de Cádiz, decimos que por quanto nosotros y otros de nuestra facçión que seruíamos en la dicha fragata que andaua pirateando en estas costas la trajimos y conduçimos rendida a la vahía de esta ciudad para que sirbiese a Su Magestad, en cuyo real nonbre la entreg[amos] al señor Don Diego de Ybarra, almirante general de la Real [Armada] como es notorio" (AHPC, Protocolos Notariales de Cádiz, leg. 738, s. fol, 19 de abril de 1667).

113 “de la fragata nombrada 'San Antonio', de quien fue capitán el Cavallero Maltés” (AHPC, Protocolos Notariales de Cádiz, leg. 4416, fol. 398, 25 de junio de 1666).

${ }^{114}$ Daba su poder "al capitán don Samuel Carington, entretenido en la dicha Real Armada, y a Rouerto Boedles, de mi mesma nación, cirujano de la dicha fragata (...) (para que) reciban y cobren la cantidad de marauedís que Su Magestad (...) fuese seruido madarme pagar por la dicha raçón” (AHPC, Protocolos Notariales de Cádiz, leg. 738, s. fol, 23 de enero de 1666).

${ }^{115}$ AHPC, Protocolos Notariales de Cádiz, leg. 4415, fols. 464-465, 20 de noviembre de 1665.
} 
Al margen de este caso, los testimonios sobre las acciones de españoles y portugueses no son abundantes. Es una cuestión importante para contextualizar los casos angloneerlandeses, pero también para dilucidar el grado de participación española en el corso inglés y holandés promovido en Cádiz, o el ejercido contra ambas naciones ${ }^{116}$. La documentación que puede encontrarse en los Protocolos Notariales de Cádiz no refleja las habituales confrontaciones que debieron desarrollarse, probablemente porque tales cuestiones serían encauzadas hacia la escribanía de guerra y esta no se ha conservado ${ }^{117}$. No obstante, las referencias a ataques entre españoles y portugueses, aunque aisladas y poco concluyentes, aun pueden rastrearse. Tal es el ejemplo de la compra de una esclava en mayo de $1666^{118}$. El capitán y sargento mayor Gabriel de la Torre, vecino de Cádiz, la vendía tras haberla adquirido de Ignacio Fragoso, criado del Duque de Aveiro, procediendo "de una presa que hiço a los portugueses"119. Otro esclavo era Juan Vello, que recibió Gabriel de la Torre del Duque como general "en el viaje que navegó en la Armada Real, de vna presa que en él se hiso a portugueçes”" ${ }^{\prime 20}$. Tal toma se había producido en 1665. En julio de 1666 La Gaceta de Londres reflejaba la información llegada desde Madrid el día 30 de junio: los españoles habían apresado y enviado a Cádiz una nave genovesa que había salido de Lisboa con cuatrocientos cincuenta cofres de azúcar, palo brasil, tabaco y algunos esclavos negros ${ }^{121}$. La justificación radicaba en el comercio con bienes pertenecientes a enemigos.

Por otra parte, corsarios de otras nacionalidades también actuaban en las aguas de golfo de Cádiz, aprovechando la situación de guerra entre las diversas potencias. Ya se ha podido ver al respecto del corsario francés Enrique Col, pero ese también fue el caso de los genoveses Pedro Jacome y Bartolomé Mechinares o de Mersenaris, capitán y teniente de capitán del navío corsante 'El Rey David' ${ }^{122}$. Si bien no se sabe la fecha exacta del

\footnotetext{
116 Sobre algunas compañías de corso españolas de aquellos años, por extensión de este artículo, deberá ahondarse en futuras investigaciones.

${ }^{117}$ Los fondos del Archivo General de Simancas han sido ampliamente estudiados por el historiador Enrique Otero Lana. Con respecto a los fondos locales, se plantea el problema de que la mayor parte de los documentos relacionados con las empresas de corso organizadas en Cádiz debieron estar aglutinados en el archivo del Departamento de Marina, destruido tras un incendio. Solo quedan, por tanto, algunas huellas entre los numerosos legajos de los Protocolos Notariales del Archivo Histórico Provincial.

${ }^{118}$ AHPC, Protocolos Notariales de Cádiz, leg. 863, fols. 99-100, 30 de mayo de 1666.

119 "vna esclaua negra atezada de naçión portuguesa nombrada María que será de treinta años, poco más o menos, de buen cuerpo, con vna señal de herida en la frente a vn lado de ella". La descripción de María cambia algo en otra venta: "negra color clara, delgada, menuda de cara, pequeña de cuerpo, de hedad de treinta años, poco más o menos, nombrada Mariana" (Ibidem, fols. 294-295, 29 de diciembre de 1665).

120 "negro atesado (...) de veinte y çinco años, poco más o menos, de buen cuerpo, rehecho, de naçión portugués" (Ibidem, fols. 292-293, 24 de diciembre de 1665). Véase también Ibidem, fol. 162, 1666.

121 The London Gazette, n. 70.

${ }^{122}$ La atribución de la nación flamenca al capitán referido en el siguiente documento estudiado parece más un error del escribano. Su nombre no denota tal origen, además de la extraña situación de un buque corsario conducido por un holandés atacando a otra nave holandesa.
} 
apresamiento, parece que no fue mucho anterior al mes de diciembre del año de 1667. Dos testimonios distintos, una fianza depositaria y un poder, dan cuenta de la presa realizada sobre “el navío nombrado 'El Negrito’, de que era capitán Pedro Nicolás Reynaldo, de nazión flamenco", que le apresó "sobre porto Oporto (sic), en las costas de Portugal"123. La justicia real actuó cuando la presa fue conducida a Cádiz por Bartolomé Mechinares, embargándola hasta determinar si era legítima o no. Su carga consistía en lana y aceite de linaza, que procedieron a descargarse para evitar que se estropearan con el paso del tiempo. 'El Negrito' quedó anclado en El Puntal ${ }^{124}$. En octubre de 1665, Andrés Realle de Marsella y Pedro Teysser de Lyon ponían en ejecución un acuerdo a la vuelta de este último de su campaña de corso. Realle había acudido a Cádiz representando también los intereses de Jacques Omar, Ples y Yanomar, otros tres franceses. Debía serle entregado el navío 'Santa Clara', que se encontraba en poder y custodia de Teysser. Sin embargo este "lo tenía armado para yr con él a corsso y fecho los gastos nessesarios para ello, por cuya causa no me pudo entregar el dicho navío" 125 . Por último, cabe señalar que las menciones a ataques de galeotas y galeras berberiscas también son abundantes en el período estudiado. El corso norteafricano, como es bien sabido, fue una constante durante toda la Edad Moderna, en especial para las aguas y litoral del sur de la Península Ibérica.

\section{Conclusiones finales}

Los hechos descritos parecen ser lo suficientemente clarificadores como para poder determinar que el ejercicio del corso en el contexto gaditano de la segunda mitad del siglo XVII fue de una relevancia comparable al que pueda constatarse en otros períodos considerados como de gran proliferación (por ejemplo, las postrimerías del siglo XV o el siglo XVIII) ${ }^{126}$. El enfrentamiento entre dos potencias eminentemente marítimas tuvo su reflejo en torno a las rutas comerciales y los puertos más activos de la época. Y en este sentido, las aguas cercanas a Cádiz fueron escenario de combates y apresamientos, y su puerto sirvió como base para corsarios de una u otra nacionalidad y sus respectivas colonias de

\footnotetext{
${ }^{123}$ AHPC, Protocolos Notariales de Cádiz, leg. 1797, fols. 68-69r, 16 de mayo de 1668.

${ }^{124}$ AHPC, Protocolos Notariales de Cádiz, leg. 4417, fol. 548, 19 de diciembre de 1667.

${ }^{125}$ AHPC, Protocolos Notariales de Cádiz, leg. 2518, fol. 207, 3 de octubre de 1665. Habían convenido "que bolviendo el dicho Pedro Teysser a la baýa desta çiudad con el dicho navío, de vuelta del dicho viaje, nonbraríamos dos personas cada uno (...) para que ajustasse lo referido, como con efecto lo hizimos, nonbrando yo, el dicho Andrés Realle, a Marco Antonio Durán; y yo, el dicho Pedro Teysser, a Françesco Montaube, sotaconsul de la naçión fransessa, anbos vezinos (...) los quales nos an ajustado en que yo, el dicho Andrés (...) pague al dicho Pedro (...) sieteçientos y sinquenta pessos de a ocho reales de plata cada uno". ${ }^{126} \mathrm{Al}$ respecto del siglo XV, véase HERNÁNDEZ SANDE, Jesús: Corso y piratería en el reino de Sevilla a finales de la Edad Media (tesis doctoral inédita), Huelva, Universidad de Huelva, 2019.
} 
comerciantes favorecieron el desarrollo de la actividad corsaria. Al menos para los años comprendidos en este breve estudio, los Protocolos Notariales de Cádiz aún son un testigo privilegiado de esta realidad y una fuente rica y de enorme interés por explorar para el estudio de la guerra naval. Si se tuvieran en cuenta en el análisis de los años que van de 1665 a 1667 otros apresamientos reflejados en los documentos notariales, en los cuales estuvieron implicados españoles, portugueses, franceses o berberiscos, la cifra total de casos llegaría a duplicarse, hasta una estimación de medio centenar en tan solo tres años.

Para un estudio profundo, global e integrador de la actividad corsaria en los siglos de la Edad Moderna sigue siendo necesaria una labor ingente de recopilación de testimonios, contenidos en la multitud de registros existentes en archivos locales y nacionales, en todos los países implicados. La realidad demuestra que, en ocasiones, solo se ha conservado una referencia aislada sobre un apresamiento o armamento. Solo entonces, con una sistematización y puesta en común, podrá comprenderse la verdadera relevancia del fenómeno y establecerse una más o menos certera consideración de los ciclos de crecimiento y proliferación del corso, las zonas o lugares donde se armaban las naves, el grado de implicación de las comunidades locales o la importancia económica de la actividad. Todo ello con la limitación de las fuentes, por supuesto, pues como ya se señalaba, los armamentos en corso españoles adolecen de una falta dramática de registros por la accidentada historia archivística hasta nuestros días.

El pequeño abanico de sucesos y circunstancias analizados en las páginas anteriores ofrece un vívido retrato sobre las operaciones navales que se desarrollaron en el contexto de la Segunda Guerra Anglo-Neerlandesa. Acciones similares se repetirían en el tiempo, cambiando de protagonistas, de circunstancias, hasta de escenarios, pero constituyéndose en una constante en la dinámica de la navegación y el comercio marítimo de la época. Algunos de los testimonios incluidos en este artículo ya apuntan a la existencia de muchas naves que, teniendo como puerto de salida o de destino el de Cádiz, fueron interceptadas, atacadas y/o apresadas por escuadras y corsarios en su ruta. En algunos casos en aguas del norte de Europa, en otros en el Mediterráneo occidental, pero también en viajes desde o hacia las Indias.

Por las propias características del conflicto y su contexto, así como por el número de testimonios estudiados, las autoridades españolas y, en específico, gaditanas, debieron permitir, si no favorecer, el ejercicio del corso por parte de los holandeses. Probablemente, también exhibirían cierta laxitud al respecto de los quebrantamientos de seguro de la neutralidad de los puertos, a tenor del número de presas realizadas a la vista o dentro del radio de acción de la artillería de las defensas portuarias. 
Entre los eventos de la guerra no se incluyen únicamente actuaciones militares regulares, considerando también como tales las resultantes del ya más que habitual ejercicio del corso, si no también pintorescos episodios de amotinamientos y actos de piratería. Con seguridad, al respecto de los segundos, estos debieron ser mayores en número de lo que podemos intuir a partir de los documentos conservados, y son una muestra más de la inestabilidad del momento.

Por último resulta también interesante reseñar que, al disponerse en esta época de fuentes protoperiodísticas, las noticias sobre las acciones piráticas y corsarias, las informaciones sobre los encuentros y escaramuzas de embarcaciones de uno u otro bando, se convertían así en parte de la maquinaria de desprestigio del rival y enaltecimiento de las victorias propias. Los hechos relativos a la fragata 'Pembroke' quizás sean paradigmáticos para entender el poder del discurso: el mismo suceso podía ser una victoria para cada una de las fuerzas enfrentadas.

\section{Apéndice 1}

\section{Cuadro resumen de apresamientos analizados (1665-1667)}

\begin{tabular}{|c|c|c|c|c|c|}
\hline Presa & Atacante & Carga & Valor & Fecha & Lugar \\
\hline $\begin{array}{l}\text { 'La Rosa' } \\
(-)\end{array}$ & $\begin{array}{l}\text { 'Thomas Elders' } \\
\text { (T. Borases, } \\
\text { Inglaterra?) }\end{array}$ & Bacalao & 2.000 reales & $1665 ?$ & $\begin{array}{l}\text { De vuelta de } \\
\text { Terranova }\end{array}$ \\
\hline $\begin{array}{l}\text { 'La Ventura' } \\
\text { (J. Cole, Inglaterra) }\end{array}$ & $\begin{array}{l}\text { 'La Judi Marchante' } \\
\text { (G. Galison, } \\
\text { Holanda) }\end{array}$ & $\begin{array}{l}\text { Jabón, } \\
\text { algodón, } \\
\text { goma... }\end{array}$ & - & $\begin{array}{l}\text { Finales de } \\
\text { mar. } 1665\end{array}$ & $\begin{array}{l}\text { Cerca de } \\
\text { Málaga }\end{array}$ \\
\hline $\begin{array}{l}\text { 'La Corona' } \\
\text { (Inglaterra) }\end{array}$ & $\begin{array}{l}\text { Escuadra de guerra } \\
\text { (Mewen, Holanda) }\end{array}$ & - & - & $\begin{array}{l}\text { Aprox. } \\
\text { mayo } 1665\end{array}$ & $\begin{array}{l}\text { Cerca de } \\
\text { Cádiz }\end{array}$ \\
\hline $\begin{array}{l}\text { 'Las Armas de } \\
\text { Inglat.' } \\
\text { (G. Hermes, } \\
\text { Inglaterra) }\end{array}$ & $\begin{array}{l}\text { 'San Carlos' } \\
\text { (D. Harcksz, } \\
\text { Holanda) }\end{array}$ & $\begin{array}{l}\text { Al menos } 2 \\
\text { esclavas }\end{array}$ & - & $\begin{array}{l}\text { Aprox. } \\
\text { mayo } 1665\end{array}$ & $\begin{array}{l}\text { Cerca de "los } \\
\text { cabos" }\end{array}$ \\
\hline $\begin{array}{l}\text { 'La Salamandra' } \\
\text { (Inglaterra) }\end{array}$ & $\begin{array}{l}\text { 'San Carlos' } \\
\text { (D. Harcksz, } \\
\text { Holanda) }\end{array}$ & $\begin{array}{l}51 \text { presos y } \\
\text { pabellón }\end{array}$ & - & $\begin{array}{l}\text { Aprox. } 21 \\
\text { mayo } 1665\end{array}$ & - \\
\hline $\begin{array}{l}\text { 'La Encarnación’ } \\
\text { (J. Pretina, Venecia) }\end{array}$ & $\begin{array}{l}\text { Navios de guerra } \\
\text { (P. Midelano, } \\
\text { Holanda) }\end{array}$ & $\begin{array}{l}\text { Lana, } \\
\text { varillas y sal }\end{array}$ & - & $\begin{array}{l}22 \text { jun. } \\
1665\end{array}$ & $\begin{array}{l}20 \text { leguas al } \\
\text { oeste del Est. } \\
\text { de Gibraltar }\end{array}$ \\
\hline $\begin{array}{l}\text { 'E1 Diamante' } \\
\text { (R. Doze, Livorno) }\end{array}$ & $\begin{array}{l}\text { Navios de guerra } \\
\text { (P. Midelano, } \\
\text { Holanda) }\end{array}$ & - & - & $\begin{array}{l}22 \text { jun. } \\
1665\end{array}$ & Idem \\
\hline $\begin{array}{l}\text { 'S. Catalina' } \\
\text { (C. Susquens, } \\
\text { Holanda) }\end{array}$ & $\begin{array}{l}\text { Nao de guerra } \\
\text { (Inglaterra) }\end{array}$ & - & - & $\begin{array}{l}\text { Aprox. } \\
\text { verano de } \\
1665\end{array}$ & $\begin{array}{l}\text { En el Elba } \\
\text { (Hamburgo) }\end{array}$ \\
\hline $\begin{array}{l}\text { 'La Fidelidad' } \\
\text { (J. Stafford, Inglaterra) }\end{array}$ & $\begin{array}{l}\text { 'S. Francisco' } \\
\text { (W. Jansen y T. } \\
\text { Aldersen, Holanda) }\end{array}$ & $\begin{array}{l}\text { Vino y } \\
\text { pasas }\end{array}$ & $\begin{array}{l}\text { Restitución } \\
\text { y pena de } \\
2.000 \\
\text { ducados }\end{array}$ & 8 oct. 1665 & $\begin{array}{l}\text { Cerca de la } \\
\text { barra de } \\
\text { Huelva }\end{array}$ \\
\hline
\end{tabular}




\begin{tabular}{|c|c|c|c|c|c|}
\hline $\begin{array}{l}\text { 'S. Antonio de } \\
\text { Padua' } \\
\text { (M. de Plussi/Plesi 'el } \\
\text { Maltés', Francia?) }\end{array}$ & $\begin{array}{l}\text { Tripulación amotinada } \\
\text { (div. nacionalidades) }\end{array}$ & $\begin{array}{l}100 \\
\text { infantes de } \\
\text { Portugal }\end{array}$ & - & Nov. 1665 & $\begin{array}{l}\text { Saliendo de } \\
\text { Cascais } \\
\text { (Portugal) }\end{array}$ \\
\hline $\begin{array}{l}\text { Navio } \\
\text { (Inglaterra) }\end{array}$ & $\begin{array}{l}\text { 'S. Juan Evangelista' } \\
\text { (P. Enríquez, } \\
\text { Holanda) }\end{array}$ & $\begin{array}{l}\text { Bacalao y } \\
\text { tabaco }\end{array}$ & - & $\begin{array}{l}\text { Aprox. } \\
1665\end{array}$ & $\begin{array}{l}\text { En el Est. de } \\
\text { Gibraltar }\end{array}$ \\
\hline $\begin{array}{l}\text { 'La Catalina Real de } \\
\text { Londres' } \\
\text { (G. Guebar y D. } \\
\text { Gorman, Inglaterra/ } \\
\text { Irlanda) }\end{array}$ & $\begin{array}{l}\text { 'El Profeta Elías' } \\
\text { (J. Gideonz. } \\
\text { Verburgh, Holanda) }\end{array}$ & $\begin{array}{l}\text { Vinos de } \\
\text { Francia }\end{array}$ & 5.358 pesos & $\begin{array}{l}17 \text { sep. } \\
1665\end{array}$ & $\begin{array}{l}\text { En el puerto } \\
\text { de Cádiz }\end{array}$ \\
\hline $\begin{array}{l}\text { 'E1 Guillermo' } \\
\text { (Inglaterra) }\end{array}$ & $\begin{array}{l}\text { 'El Profeta Elías' } \\
\text { (J. Gideonz. } \\
\text { Verburgh, Holanda) }\end{array}$ & - & - & $\begin{array}{l}\text { Finales de } \\
1665 \text { o } \\
\text { inicios de } \\
1666\end{array}$ & - \\
\hline $\begin{array}{l}\text { 'S. Pedro' } \\
\text { (H. Gerardo, } \\
\text { Holanda) }\end{array}$ & $\begin{array}{l}\text { Escuadra de guerra } \\
\text { (J. Sinitt, Inglaterra) }\end{array}$ & - & - & $\begin{array}{l}\text { Aprox. } \\
1666\end{array}$ & $\begin{array}{l}\text { En la bahía } \\
\text { de Cádiz }\end{array}$ \\
\hline $\begin{array}{l}\text { 'S. Carlos' } \\
\text { (J. de Lahid, } \\
\text { Inglaterra) }\end{array}$ & $\begin{array}{l}\text { 'El Mercurio' } \\
\text { (J.C. Dorp y A. } \\
\text { Adriansen, Holanda) }\end{array}$ & $\begin{array}{l}\text { Vino, } \\
\text { pasas, } \\
\text { almendras, } \\
\text { papel y loza }\end{array}$ & $\begin{array}{l}\text { Subastada } \\
\text { en } 14.000 \\
\text { reales }\end{array}$ & $\begin{array}{l}\text { Aprox. jul. } \\
1666\end{array}$ & $\begin{array}{l}\text { En el puerto } \\
\text { de Sanlúcar } \\
\text { de } \\
\text { Barrameda }\end{array}$ \\
\hline $\begin{array}{l}\text { 'S. Catalina' } \\
\text { (J.J. de Blanes, catalán) }\end{array}$ & - & Trigo & $\begin{array}{l}\text { Revendida } \\
\text { en Tánger } \\
\text { por } 307 \\
\text { pesos }\end{array}$ & $\begin{array}{l}\text { Aprox. } \\
\text { inicios de } \\
1667\end{array}$ & - \\
\hline - & $\begin{array}{l}\text { 'El Grifo' } \\
\text { (Holanda) }\end{array}$ & - & - & $\begin{array}{l}\text { Aprox. } \\
\text { mar. } 1667\end{array}$ & $\begin{array}{l}\text { Yendo a } \\
\text { Málaga desde } \\
\text { Cádiz }\end{array}$ \\
\hline - & $\begin{array}{l}\text { 'El Príncipe } \\
\text { Guillermo III' } \\
\text { (J. Gerardo/ Backer, } \\
\text { Holanda) }\end{array}$ & - & - & $\begin{array}{l}\text { Aprox. } \\
\text { mar. } 1667\end{array}$ & - \\
\hline $\begin{array}{l}\text { 'La Tanr }[. . .] \text { ina' } \\
\text { (Inglaterra) }\end{array}$ & $\begin{array}{l}\text { 'S. Luis' } \\
\text { (E. Col, Francia?/ } \\
\text { Alemania?) }\end{array}$ & - & $\begin{array}{l}\text { Vendido } \\
\text { por } 1.600 \\
\text { pesos }\end{array}$ & $\begin{array}{l}\text { Aprox. abr. } \\
1667\end{array}$ & $\begin{array}{l}\text { En la costa } \\
\text { de Sancti } \\
\text { Petri }\end{array}$ \\
\hline $\begin{array}{l}\text { 'El Sacrificio de } \\
\text { Abraham' } \\
\text { (A. Bazo, Génova?) }\end{array}$ & - & - & - & $\begin{array}{l}\text { Aprox. jun. } \\
1667\end{array}$ & $\begin{array}{l}\text { Yendo de } \\
\text { Texel a la } \\
\text { bahía de } \\
\text { Cádiz }\end{array}$ \\
\hline $\begin{array}{l}\text { 'La Paz' } \\
\text { (A. Colen, Holanda) }\end{array}$ & $\begin{array}{l}\text { 'S. Luis' } \\
\text { (E. Col, Francia?/ } \\
\text { Alemania?) }\end{array}$ & Duelas & $\begin{array}{l}\text { Daños } \\
\text { valorados } \\
\text { en } 700 \\
\text { pesos }\end{array}$ & $\begin{array}{l}18 \text { nov. } \\
1667\end{array}$ & $\begin{array}{l}\text { Naufragó en } \\
\text { Chipiona }\end{array}$ \\
\hline $\begin{array}{l}\text { 'E1 Negrito' } \\
\text { (P. N. Reinaldo, } \\
\text { Holanda) }\end{array}$ & $\begin{array}{l}\text { 'El Rey David' } \\
\text { (P. Jacome y B. } \\
\text { Mechinares,Génova) }\end{array}$ & $\begin{array}{l}\text { Lana y } \\
\text { aceite de } \\
\text { linaza }\end{array}$ & - & c. dic. 1667 & $\begin{array}{l}\text { En la costa } \\
\text { portuguesa, } \\
\text { sobre } \\
\text { Oporto }\end{array}$ \\
\hline
\end{tabular}

\section{Apéndice 2}

20 de octubre a 15 de noviembre de 1666.

Pregón de venta de la presa 'San Carlos' en Cádiz, pujas y remate en subasta pública.

AHPC, Protocolos Notariales de Cádiz, leg. 1797, fols. 3-8 
"Pregón.

En la çiudad de Cádiz, a veinte días del mes de otubre de mil y seiszientos (sic) y sesenta y seis años, de pedimento de Juan Duncan, honbre de negozios de la nazión ynglesa, residente en esta ciudad, en nonbre y con poder de los ynteresados en el navío nonbrado 'San Carlos' y su carga; Manuel Moreno, pregonero, en altas voses pregonó diciendo:

Quien quisiere comprar el navío nonbrado 'San Carlos', que será de porte de ochenta toneladas, poco más o menos, con todos sus árboles, belas, harcia y peltrechos, y las armas y mercadurías siguientes: quatro pedreros y seis cámaras; ciento y setenta y nueve botijuelas de aceite; quarenta y una botijas de vino tinto; honce barriles de passa; trece sacos de almendra; un barril grande de almendra; siete balones de papel; tres cajas de jabón, de las quales falta de vna la quarta parte; diez pipas de vino; siete barriles de vino; un barril de alquitrán medio baçío; sesenta y seis estrengues de esparto, chicos y grandes; ocho serones con sogas de esparto menudos; quinçe canastas de losa de Talabera fina, de las quales ay dos medio vaçías; algunos barriles con brebaje, agua y provisión de la nao; una partida de losa basta de Lebrixa, de escudillas, platos, lebrillos y harros a granel; una partida de corchas, en que abrá un millar, $/ /{ }^{3 v}$ poco más o menos; una partida de sal que está por lastre tendida de popa a proa. Todo lo qual está dento del dicho navío por ynbentario jurídico, como parese por autos ante el presente scrivano, y es el mismo navío y carga que apresó, dentro de la barra de Sanlúcar de Barrameda, Juan Carlos Deorp (sic), theniente de la saetía de corso nonbrada 'el Mercurio', y se vende en nonbre y con poder de los ynteresados en el dicho navío y su carga. Quien quisiera hacer postura paresca ante el presente scrivano, que se le admitirá.

Y no ubo ponedor, de que doy fee.

Firma: Joan Rodríguez de Medinilla, scrivano público.

(Se continuó pregonando en la plaza de la ciudad los días 21, 22, 23, 25, 26, 27, 29 y 30 del mes de octubre, y los días 2, 3, 4, 5, 6, 8, 9, 10,11, 12, 13 y 15 de noviembre).

Postura.

En la ciudad de Cádiz, a quinze días del mes de nobienbre de mill y seiszientos y sesenta y seis años, el dicho pregonero dio otro pregón como el primero, / / ${ }^{6 r}$ y parezió Benito Ramíres, que así se dijo llamar y ser residente en esta ciudad. Y dijo que hava (sic) y hizo postura en el nabichuelo que se está pregonando, nonbrado 'San Carlos', y sus árboles, belas, armas, carga y lo demás que se espresa en el primer pregón, en diez mill reales de plata. Que se obligó a pagar luego que se le remate y se le entregue el dicho navío y su carga. Para lo qual obligó su persona y vienes avidos y por aver, y dio poder en forma de las justicias de Su Magestad. Y renunzió a las leies de su fauor. Y no lo firmó porque dijo no saber escrivir. A su ruego lo firmó un testigo, que lo fueron presente (sic) Lucas Rodrígues, Lucas Moreno de Lara y Juan de los Reies, vezinos de Cádiz.

Y se pregonó la dicha postura, y no ubo maior ponedor. De que doy fe y lo firmé.

Firma: Lucas Moreno de Lara.

Firma: Joan Rodríguez de Medinilla, scrivano público.

(Se continuó pregonando la postura en la plaza de la ciudad los días 16, 17, 18, 19, 20 y 22 de noviembre).

Otro y puja.

En la ciudad de Cádiz, a veinte y dos del dicho mes y año, el dicho pregonero stando en la plaça pública desta çiudad, pregonó la dicha postura y parezió / / 7r Joan Garçía, vezino desta çiudad. Y dijo que sobre los diez mill reales que stán (sic) dando por el dicho navío, árvoles, velas, armas, harçia y carga, haçía puja de dos mill reales de plata. Y lo dejó puesto todo ello en doze mill reales de plata, que se obligó de pagar luego que le sea rematado, libre de derechos. Para lo qual obligó su persona y vienes avidos y por aver, dio poder cunplido a 
las justizias de Su Magestad en forma y renunzió las leies de su favor, y lo firmó. El qual doy fee que conozco. Y fueron testigos Lucas Rodríguez, Lucas Moreno de Lara y Juan de los Reies, vezinos de Cádiz. Y se pregonó la dicha postura y no ubo maior ponedor, de que doy fee.

Firma: Medinilla, escrivano.

Pregón y asignazión de remate.

En la ciudad de Cádiz, a veinte y tres días del mes de nobienbre del dicho año, el dicho pregonero, de pedimiento del dicho Juan Duncan, pregonó la dicha postura y asignó el remate para el lunes veinte y nueve deste mes de nobienbre a las quatro de la tarde, que se a de hazer en el maior ponedor. De que doy fe y lo firmé.

Firma: Medinilla, escrivano.

(Se continuó pregonando en la plaza de la ciudad los días 24, 25, 26 y 27 de noviembre).

\section{Remate.}

En la ciudad de Cádiz a veinte y nueve días del mes de nobienbre de mill y seiszientos sesenta y seis años, Manuel Moreno, pregonero, stando en la plaça pública desta çiudad, en altas voçes, pregonó diziendo:

Doze mill reales //8r de plata (tachado: en la plaça pública) stán dando por el nabichuelo nonbrado 'San Carlos', con toda su carga, árvoles, velas, harcia y artillería, conforme el ynventario de que se haze mençión en el primero pregón. Y se a de rematar sta tarde a ora de las quatro, en el maior ponedor.

Y repitió el dicho pregón diferentes veçes y aviendo dado la dicha hora de las quatro, le volvió a repetir. Y parezió presente Albar Sánchez, residente en sta çiudad. Y dijo que sobre los dichos doze mill reales pujava mill reales de plata. Y lo dejó puesto en treze mill reales de plata. Y se pregonó la dicha postura.

Y parezió Esmerejildo de Torres, vezino desta ciudad. Y dijo que sobre los dichos treze mill reales de plata pujava mill reales de plata. Y lo dejó puesto el dicho navío y su carga en catorze mill reales de plata, que se obligó de pagar de contado luego que se le entregue el dicho navío y su carga.

Y el dicho pregonero, de pedimiento del dicho Juan Duncan, que stá pressente, repitió la dicha puja y postura, y aperçibió el remate, diziendo:

Catorze mill reales de plata stán dando por el dicho navío nonbrado 'San Carlos' y sus peltrechos, árvoles, velas, harçia y artillería, y se a de rematar aora en el maior ponedor. Aperçivo el remate a la una, a las dos, a la tercera que es buena y verdadera. Pues que no ay quien puje ni quien dé más por el dicho navío y su carga, árvoles, velas, harçia y artillería; / /8v que buena pro, que buena pro, que buena pro le haga a quien le tiene puesto.

Con que quedó rematado en el dicho Esmerejildo de Torres, como en maior ponedor. El qual açetó el remate y se obligó a la paga de la dicha cantidad. Y el dicho Juan Duncan, en nonbre de sus partes, consintió y aprovó el dicho remate. Y se obligó de hazer el entrego del dicho navío, árvoles, velas, harçia, artillería y carga en la forma que de presente stá, y según se espresa y declara en el primero pregón. Para lo qual obligó la persona y vienes de sus partes por su poder obligados. Y anbos lo otorgaron así, firmaron de sus nonbres, a quien doy fe que conozco. Siendo testigos Lucas Moreno de Lara, Lucas Rodríguez y Juan de los Reies, vezinos de Cádiz.

Firma: Juan Duncan.

Firma: Hermenexildo de Torres.

Firma: Joan Rodríguez de Medinilla, scrivano público.” 